$1^{-8^{2}} \cdot \mp-5465$

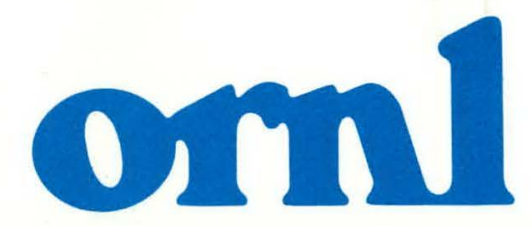

\section{OAK \\ RIDGE}

NATIONAL

LABORATORY

UNION

CARBIDE

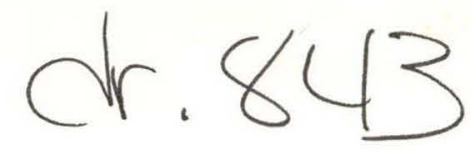

ORNL/TM-8283

ENDF-325

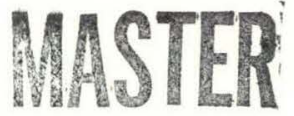

Summary of ENDF/B-V Evaluations for Carbon, Calcium, Iron, Copper, and Lead and ENDF/B-V Revision 2 for Calcium and Iron

C. Y. Fu 


\section{DISCLAIMER}

This report was prepared as an account of work sponsored by an agency of the United States Government. Neither the United States Government nor any agency Thereof, nor any of their employees, makes any warranty, express or implied, or assumes any legal liability or responsibility for the accuracy, completeness, or usefulness of any information, apparatus, product, or process disclosed, or represents that its use would not infringe privately owned rights. Reference herein to any specific commercial product, process, or service by trade name, trademark, manufacturer, or otherwise does not necessarily constitute or imply its endorsement, recommendation, or favoring by the United States Government or any agency thereof. The views and opinions of authors expressed herein do not necessarily state or reflect those of the United States Government or any agency thereof. 


\section{DISCLAIMER}

Portions of this document may be illegible in electronic image products. Images are produced from the best available original document. 


\section{Printed in the United States of America. Available from National Technical Information Service \\ U.S. Department of Commerce \\ 5285 Port Royal Road, Springfield, Virginia 22161 \\ NTIS price codes-Printed Copy: A04; Microfiche A01}

This report was prepared as an account of work sponsored by an agency of the United States Government. Neither the United States Government nor any agency thereof, nor any of their employees, makes any warranty, express or implied, or assumes any legal liability or responsibility for the accuracy, completeness, or usefulness of any information, apparatus, product, or process disclosed, or represents that its use would not infringe privately owned rights. Reference hiereiı to any specific commercial product, process, or service by trade name, trademark, manufacturer, or otherwise, does not necessarily constitute or imply its endorsement, recommendation, or favoring by the United States Government or any agency thereof. The views and opinions of authors expressed herein do not necessarily state or reflect those of the United States Government or any agency thereof. 
This repart was prepared as an nccount of work sponsored by an agency of the United States Government warranty, express or or Government nor ony agency thereat, nor any of their employees, makes any completeness. of usefulness of eny information, apparatus, product, of process disclosed. or epresents that its use would not infringe privately owned righis. Reference herein to any specifit commercial product, process, or service by trade name, trademark, manutectures, or otherwise, dow not necessarly constitute or imply is endorsentent, recommendation, or lavoring by tha Unilce States Government or any agancy thereol. The views and opinions of authors expressed herein do not necessserily state or reflect those of tha United States Government or any agency thereod.

Engineering Physics Division
DE82 021115

\section{ORNL/TM-8283}

ENDF-325

Distribution Category UC-79d

SUMMARY OF ENDF/B-V EVALUATIONS FOR CARBON, CALCIUM, IRON, COPPER, AND LEAD AND ENDF/B-V REVISION 2 FOR CALCIUM AND IRON

C. Y. Fu

NOTICE This document contains information of a preliminary nature.

It is subject to revision or correction and therefore does not represent a final report.

Manuscript Completed - May 1, 1982

Date Published - September 1982

Prepared for the

U.S. Defense Nuclear Agency

Under Interagency Cost Reimbursement Urder DNA Nuinber 81.831

and the

U.S. Department of Energy

Reactor Research and Technology Division

Prepared by.

OAK RIDGE NATIONAL LABORATOY

Oak Ridge, Tennessee 37830

operated by

UNION CARBIDE CORPORATION

for the

U.S. DEPARTMENT OF ENERGY

Under Contract No. W-7405-eng-26 


\section{THIS PAGE}

\section{WAS INTENTIONALILY \\ $\therefore \quad \mathbb{E F T}$ BLANK}




\section{CONTENTS}

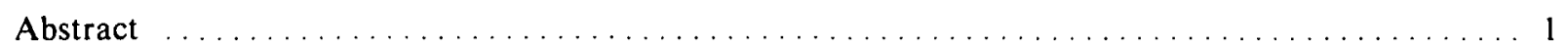

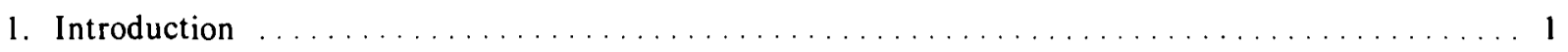

2. Updates for Carbon (ENDF/B-V MAT 1306) $\ldots \ldots \ldots \ldots \ldots \ldots \ldots \ldots \ldots \ldots \ldots \ldots$

2.1 Secondary Neutron Energy Distribution from the ${ }^{12} \mathrm{C}\left(\mathrm{n}, \mathrm{n}^{\prime} 3 \alpha\right)$ Reaction $\ldots \ldots \ldots \ldots \ldots .3$

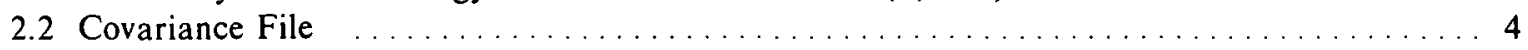

3. Updates for Calcium (ENDF/B-V MAT 1320) $\ldots \ldots \ldots \ldots \ldots \ldots \ldots \ldots \ldots \ldots \ldots \ldots \ldots$

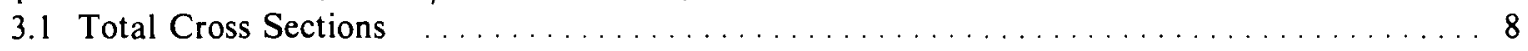

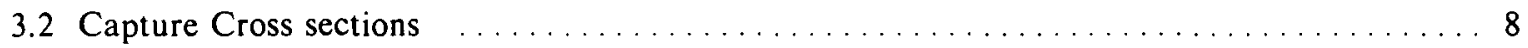

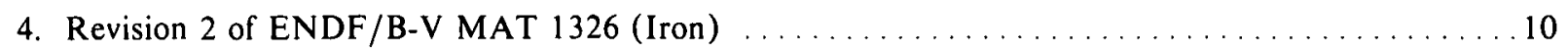

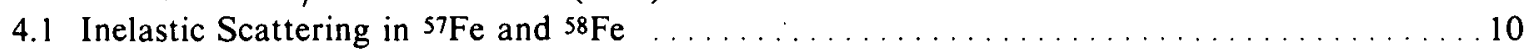

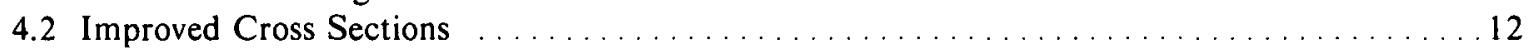

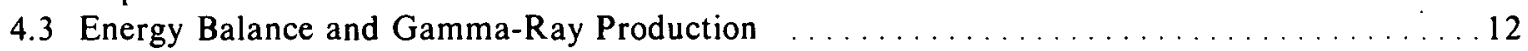

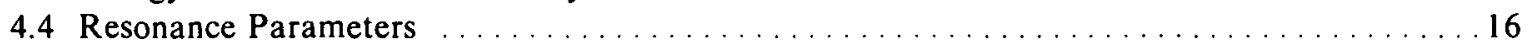

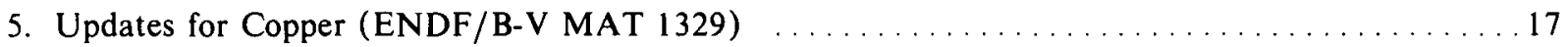

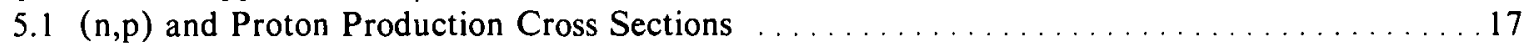

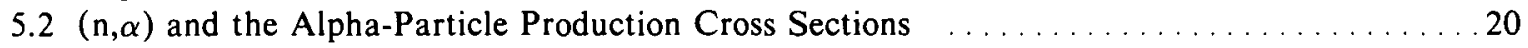

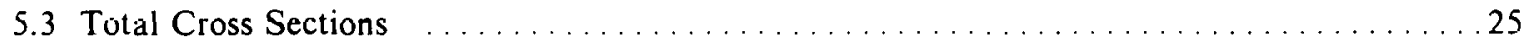

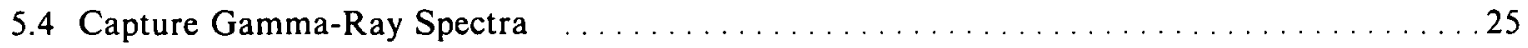

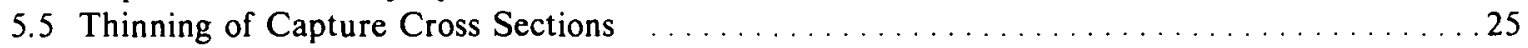

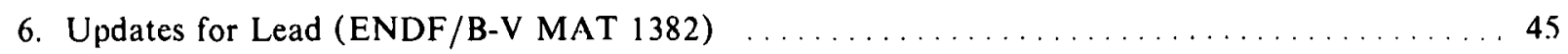

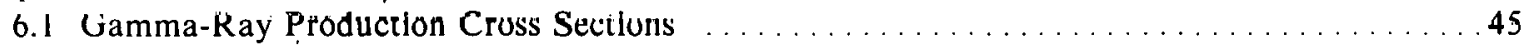

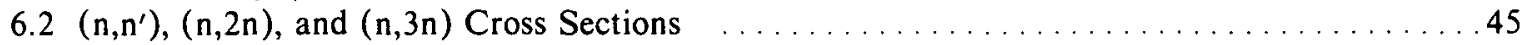

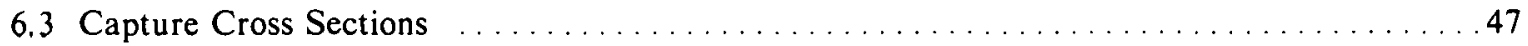

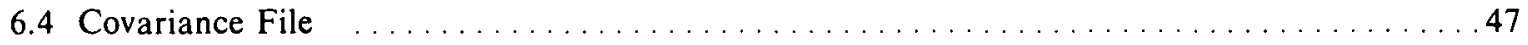

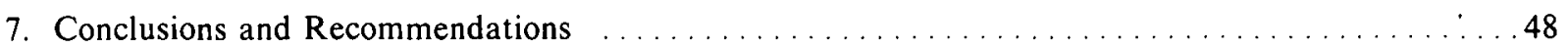

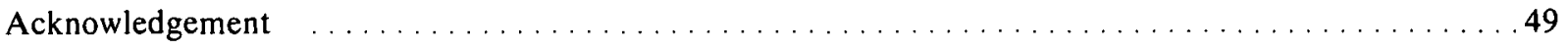

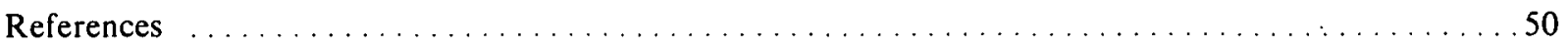




\title{
SUMMARY OF ENDF/B-V EVALUATIONS FOR CARBON, CALCIUM, IRON, COPFER, AND LEAD AND ENDF/B-V REVISION 2 FOR CALCIUM AND IRON
}

\author{
C. Y. Fu
}

\begin{abstract}
This report, together with documents already published, describes the ENDF/B-V evaluations of the neutron and gamma-ray-production cross sections for carbon, calcium, iron, copper, and lead and the ENDF/B-V Revision 2 evaluations for calcium and iron.
\end{abstract}

\section{INTRODUCTION}

The evaluations of the neutron and gamma-ray-production cross sections for calcium, iron, and lead began with ENDF/B-III and continued to ENDF/B-V. We were given the responsibility for the carbon evaluation for ENDF/B-IV and the copper evaluation for ENDF/B-V. Further revisions of ENDF/B-V were made in 1981 for calcium and iron. Reports were issued for all the major evaluation efforts. Nuclear model developments and calculations associated with these evaluations have also been published. Minor updates, as well as materials not appropriate for journal articles, are covered in this report. The published works are listed below.

Carbon. The ENDF/B-V evaluation for carbon for incident neutron energies, $\mathrm{E}_{n}$, less than 4.81 $\mathrm{MeV}$, the threshold of the first excited state of ${ }^{12} \mathrm{C}$, has been published. ${ }^{1}$ The evaluation was aided by $\mathrm{R}$-matrix and variance-covariance analyses. The part for $\mathrm{E}_{n}<2 \mathrm{MeV}$ has been adopted as the ENDF/B-V scattering standard ${ }^{2}$ for cross-section measurements. The higher energy part of the evaluation is described in Sect. 2.

Calcium. The evaluations for ENDF/B-IV and some major updates for ENDF/B-V were published together. ${ }^{3}$ The evaluation was based on a consistent calculation for neutron and gamma-ray-production cross sections will a twöstep Ilauscr-Feshbach model. Some minnr updates for ENDF/B-V are covered in Sect. 3. A further revision of ENDF/B-V has already been documented. ${ }^{4}$ 
Iron. The ENDF/B-V evaluation has been documented. ${ }^{5,6}$ Calculational aspects of this evaluation, unchanged since ENDF/B-IV, have also been documented. ${ }^{7}$ The calculation was similar to that for calcium but included precompound effects. An evaluation of thermal and resonance capture gamma-ray yields, used since ENDF/B-III, has been separately documented. ${ }^{8}$ A further revision of ENDF/B-V (to be released as ENDF/B-V Revision 2 in 1982) is described in Sect. 4.

Copper. Minor updates for ENDF/B-V are described in Sect. 5. Nuclear model calculations for ${ }^{63} \mathrm{Cu}$ which were used to aid the evaluation have been given elsewhere. ${ }^{9}$

Lead. The ENDF/B-III evaluation and part of the ENDF/B-IV evaluation were described in detail $^{10}$ and remain mostly valid. The calculational part was repeated for ENDF/B-IV to include precompound effects similar to those used for iron; ${ }^{7}$ it has not been documented yet. A summary of ENDF/B-IV and minor updates for ENDF/B-V are described in Sect. 6.

Only the evaluations for the ENDF/B-V general-purpose files are reported here. The evaluations for the ENDF/B-V dosimetry file and activation file will be reported elsewhere. 


\section{UPDATES FOR CARBON (ENDF/B-V MAT 1306)}

Our evaluation for carbon for $E_{n}<4.81 \mathrm{MeV}$ has been published. ${ }^{1}$ The evaluation for $E_{n}>4.81$ $\mathrm{MeV}$ is described below.

When work began on carbon for ENDF/B-V, a well-documented French update of ENDF/B-IV had become available." The French evaluation by Lashkar et al. " for $E_{n}<4.81 \mathrm{MeV}$ was taken from ENDF/B-IV and the part for $\mathrm{E}_{n}$ between 4.81 and $8.5 \mathrm{MeV}$ was essentially the same as ENDF/B-IV; however, the part for $E_{n}>8.5 \mathrm{MeV}$ was substantially improved with newly available data. This was adopted for ENDF/B-V except for the secondary neutron energy distributions from the $\left(n, n^{\prime} 3 \alpha\right)$ reaction. A covariance file was also added for ENDF/B-V.

\subsection{SECONDARY NEUTRON ENERGY DISTRIBUTION FROM THE ${ }^{12} \mathrm{C}\left(\mathrm{n}, \mathrm{n}^{\prime} 3 \alpha\right)$ REACTION}

Two reasons prompted us to revise the secondary neutron-energy distributions from the $\left(n, n^{\prime} 3 \alpha\right)$ reaction. First, the distributions given in the French evaluation ${ }^{11}$ for $E_{n}>15 \mathrm{MeV}$ disagree with those inferred from measured alpha-particle energies by Frye et al. ${ }^{12}$ For example, for $\mathrm{E}_{n}=20 \mathrm{MeV}$, the measurement indicates that $70 \%$ of the outgoing neutrons are below $5 \mathrm{MeV}$, while the French evaluation has $10 \%$. In addition, a large portion of secondary neutrons was given in the French evaluation as the continuum (MT91), but it is desirable to represent them as discrete-level excitations so energy-angle kinematics can be accounted for by the existing processing codes.

In the present evaluation, in accordance with Antolkovic and Dolenec, ${ }^{13}$ the reaction sequence ${ }^{12} \mathrm{C}\left(\mathrm{n}, \mathrm{n}^{\prime}\right)^{12} \mathrm{C}(\alpha)^{8} \mathrm{Be}(2 \alpha)$ was assumed to account for $90 \%$ of the cross section and the sequence ${ }^{12} \mathrm{C}(\mathrm{n}, \alpha){ }^{9} \mathrm{Be}(\mathrm{n}){ }^{8} \mathrm{Be}(2 \alpha)$ account for the remaining $10 \%$. Three other possible reaction sequences had no significant contributions up to $20 \mathrm{MeV} \cdot{ }^{11,13}$ A detailed description of the reaction mechanisms and a review of the available literature are given in ref. 11 .

A calculation based on the Hauser-Feshbach formalism was used to provide the $\left(n, n^{\prime}\right)$ part of the distributions. Ten levels of ${ }^{12} \mathrm{C}$ up to $14 \mathrm{MeV}$, as given in the French evaluation, were used in the calculation. The spin of the $11.83-\mathrm{MeV}$ level was changed from 2 to 1 , according to Antolkovic and Hudomalj. ${ }^{14}$ A level density was used for levels above $14 \mathrm{MeV}$. The density was adjusted to reproduce 
the trend ${ }^{12}$ in distributions as a function of incident neutron energy. However, the 14-MeV distribution was more strongly influenced by the data of Antolkovic and Delenec. ${ }^{13}$ It should be noted that the calculation had little physical basis and was used strictly for extrapolation. The calculation was normalized to $90 \%$ of the evaluated cross section for each incident neutron energy and was given in the file as discrete-level excitations.

As for the ${ }^{12} C(n, \alpha)$ sequence, the French evaluation was followed, and an evaporation spectrum with a temperature of $0.3 \mathrm{MeV}$ was used.

The resulting distribution for 14-MeV incident neutron is shown in Fig. 1. The cross sections for exciting the four lowest levels above the absolute $\mathrm{Q}$-value $(7.275 \mathrm{MeV})$ are given as rectangles with half widths equal to half of the level widths. ${ }^{11}$ The cross sections for higher energy levels were lumped with the continuum and given as rectangles with half widths equal to $0.25 \mathrm{MeV}$. For processing codes that cannot handle level widths, all the cross sections in the ${ }^{12} \mathrm{C}\left(n, n^{\prime}\right)^{12} \mathrm{C}(\alpha)^{8} \mathrm{Be}(2 \alpha)$ sequence can be treated as discrete levels. The small evaporation spectrum in Fig. 1 represents the other reaction sequence. To see the spectrum better, the various components were broadened into $0.5-\mathrm{MeV}$ bins and summed as in Fig. 2. This spectrum, if further broadened so that the dip at $10 \mathrm{MeV}$ would almost disappear, would look like the ones experimentally inferred. ${ }^{12,13}$ The absolute cross sections for exciting the first few lev= els are uncertain because they were not clearly resolved experimentally. The mixture of $90 \%$ and $10 \%$ for the two major reaction sequences may be reasonable at $14 \mathrm{MeV}$, but not necessarily at other energies. However, the gaps in the spectrum are correctly reproduced.

\subsection{COVARIANCE FILE}

Covariance data are given for total, elastic, nonelastic, $\left(n, n^{\prime}\right),(n, n 3 \alpha),(n, \gamma),(n, p),(n, d)$, and $(n, \alpha)$ cross sections. Derived sections (NC subsections) reflect how the cross-section files were generated.

For total and clastic scattering above $2 \mathrm{MeV},\left(n, n^{\prime}\right)$ and $(n, \alpha)$ cross-section cuvariances were determined from $\pm 2 \sigma$ error bands. The error bands were extended and enlarged to cover energy regions lacking experimental data. In general, long-range covariances reflect systematic errors common to all data sets. Medium-range covariances reflect the difference in energy coverage by different data sets and the difference in the experimental methods within the same data set. Short-range covariances 
ORNL - DWG 82-9815

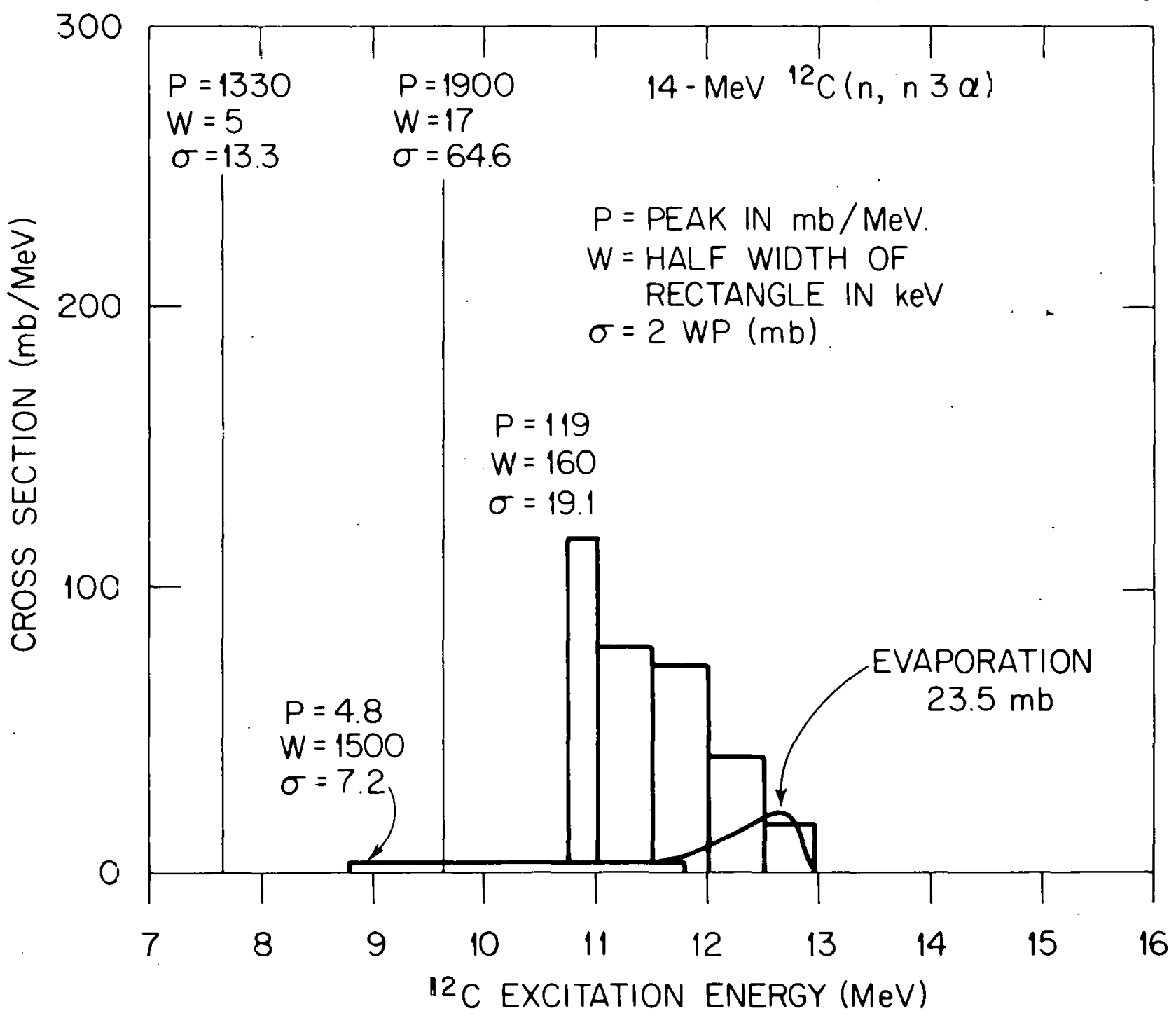

Fig. 1. Excitation cross sections of the discrete levels and continuum bins of ${ }^{12} \mathrm{C}$ in the ${ }^{12} \mathrm{C}\left(\mathrm{n}, \mathrm{n}^{\prime} 3 \alpha\right)$ reaction as given in the ENDF/B-Y file. 


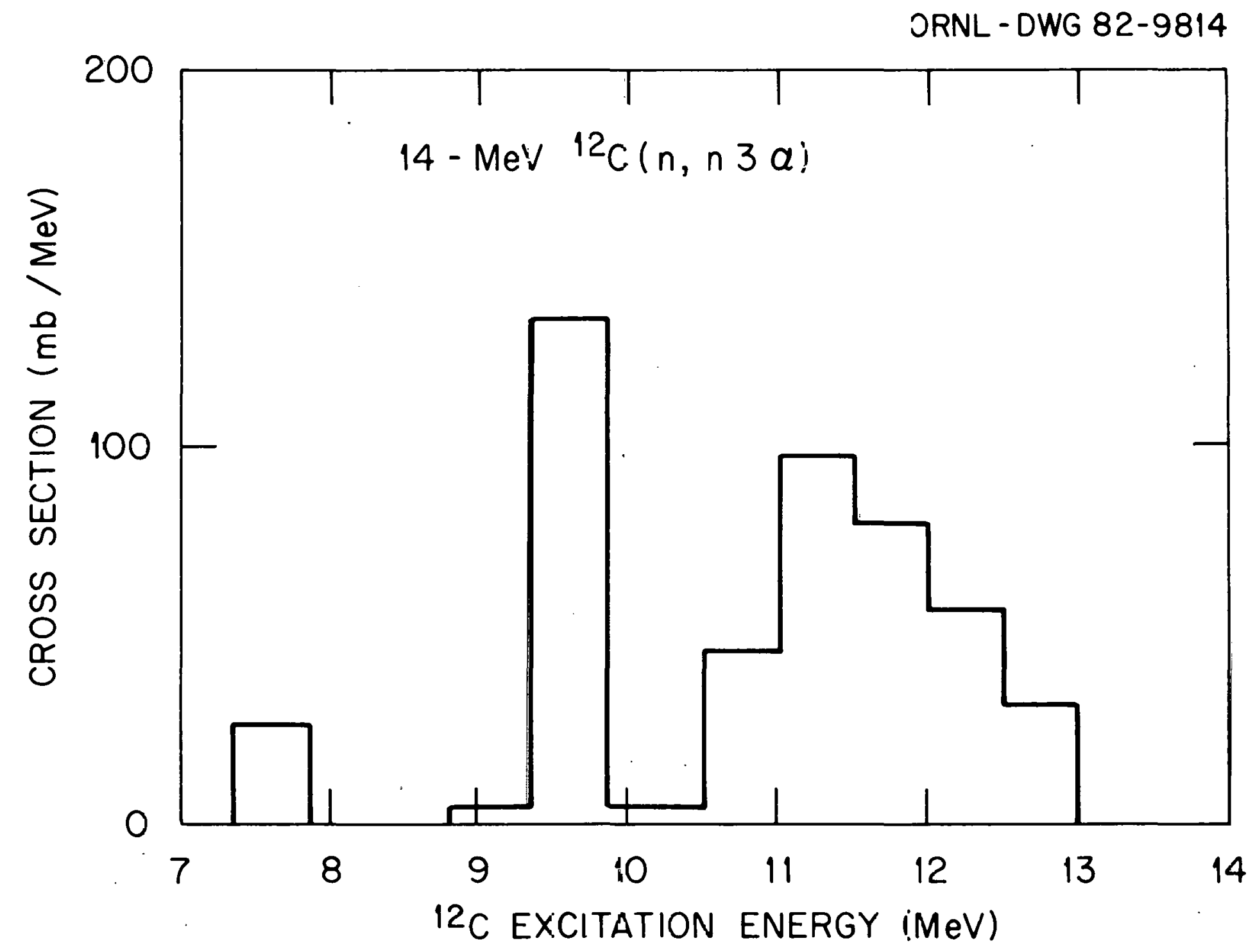

Fig. 2. The spectral components in Fig 1 are broadened into $0.5-\mathrm{MeV}$ bins and summed. 
reflect structures in the cross sections and/or threshold effects. Statistical errors are nonexistent in the evaluated cross sections.

For elastic scattering below $2 \mathrm{MeV}$, covariances were evaluated individually for each of six data sets. These six data sets and their covariances were averaged by generalized least-squares (Bayes theorem, see ref. 1). The resulting covariances were further modified by considering the effects of the R-matrix fit which included thermal data, data above $2 \mathrm{MeV}$, and polarization data. Uncertainties (not covariances) in the angular distributions were evaluated and reported in ref. 1. The latter information was not given in the file because covariance formats for angular distributions have not been developed yet.

Seventeen components (either discrete levels or bands of continuum levels) represent the $\left(n, n^{\prime} 3 \alpha\right)$ reaction cross sections. A $20 \%$ fully-correlated uncertainty is given to each component. 


\section{UPDATES FOR CALCIUM (ENDF/B-V MAT 1320)}

The evaluation for ENDF/B-IV and the subsequent revision for ENDF/B-V, except as noted below, have been published together. ${ }^{3}$ The ENDF/B-V evaluation was based on a model calculation more advanced than that used for Version IV. For ENDF/B-IV, the reaction cross sections experimentally available below the tertiary reaction threshold (about $8 \mathrm{MeV}$ ) were consistently interpreted with the Hauser-Feshbach model with width-fluctuation corrections, but the higher energy part was based on an evaporation model. The latter part of the calculations was repeated for ENDF/B-V following the development of the TNG code ${ }^{3}$ which calculates consistently the binary and tertiary reaction cross sections in the Hauser-Feshbach model. It was shown ${ }^{3}$ that gamma-ray production spectra from tertiary reactions, such as ${ }^{40} \mathrm{Ca}(\mathrm{n}, \mathrm{np})$, are sensitive to spin variations and can be reproduced with the new code.

Two minor additional updates for ENDF/B-V are summarized below.

\subsection{TOTAL CROSS SECTIONS}

Total cross sections from $100 \mathrm{eV}$ to $50 \mathrm{keV}$ were decreased by about $200 \mathrm{mb}$ according to a new high-quality measurement. ${ }^{15}$ The new data, some old data, and the ENDF/B-IV values are all graphically shown in BNL-325. ${ }^{16}$ The values of the new measurcment ${ }^{15}$ were chosen for F.NDF/B=V.

\subsection{CAPTURE CROSS SECTIONS}

Capture cross sections from 25 to $200 \mathrm{keV}$ were increased by a factor of 2 to 5 according to recent ORELA data. ${ }^{17,18}$ Since resonance parameters are not given in the evaluated files, the cross sections averaged by the experimentalists were used directly as shown in Fig. 3. ENDF/B-IV values are also shown. The cross sections above $200 \mathrm{keV}$ were assumed to decrease, reach a minimum near $5 \mathrm{MeV}$, increase, and go through a $14-\mathrm{keV}$ value measured by Cvelbar. ${ }^{19}$ 


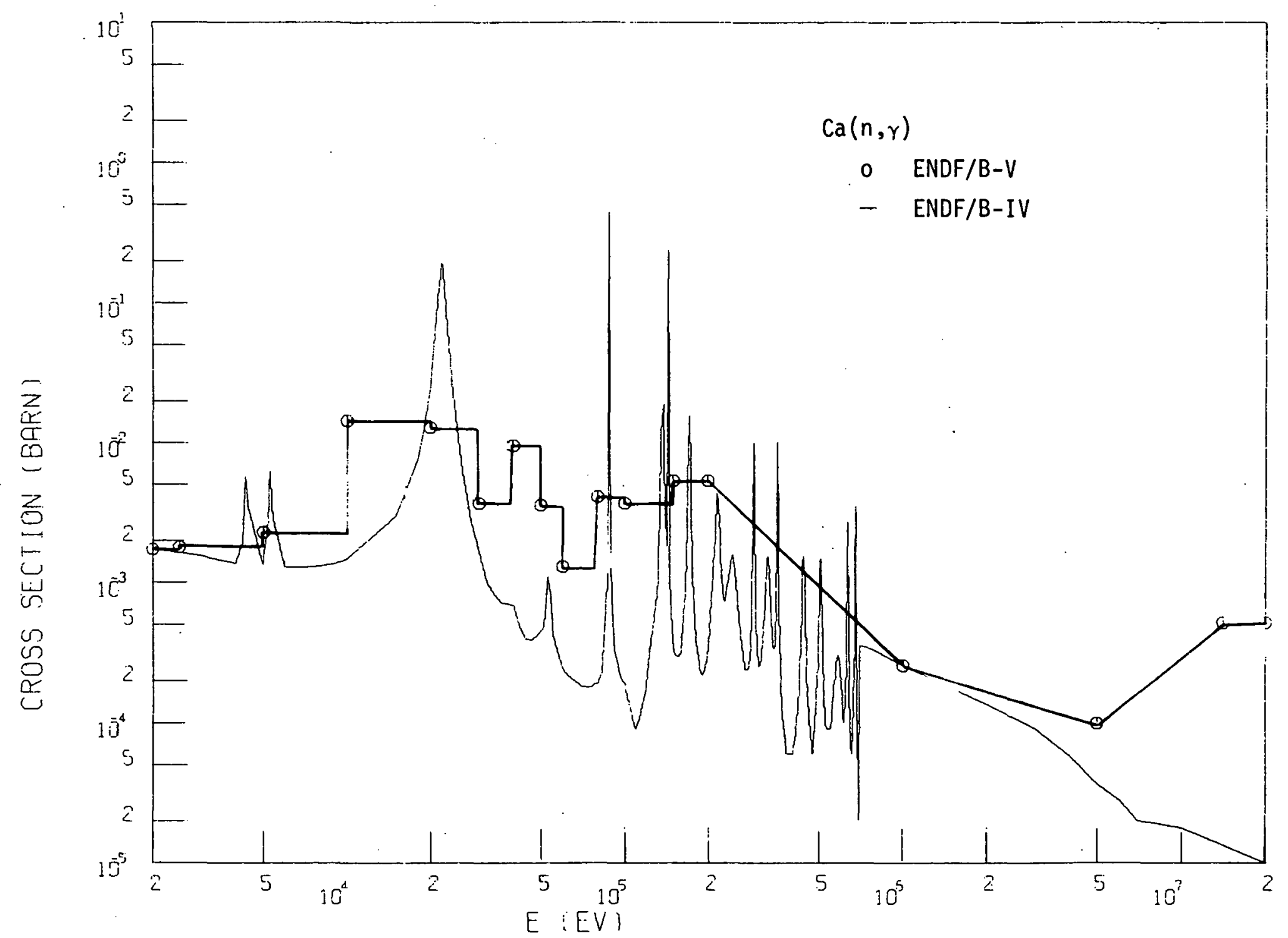

F:g. 3. The $\mathrm{Ca}(\mathrm{n}, \gamma)$ cross sections in ENDF/B-IV and $-\mathrm{V}$. The ENDF/B-V values between $2 \mathrm{keV}$ and $200 \mathrm{keV}$ are ORELA data. ${ }^{17,18}$ 


\section{REVISION 2 OF ENDF/B-V MAT 1326 (IRON)}

Revisions were made in four areas to the ENDF/B-V evaluation ${ }^{5,6}$ for iron and is summarized below. This version will be released in 1982 as ENDF/B-V Revision 2.

\subsection{INELASTIC SCATTERING IN ${ }^{57} \mathrm{Fe}$ AND ${ }^{58} \mathrm{Fe}$}

The cross sections for inelastic scattering to 21 levels in ${ }^{57} \mathrm{Fe}$ and two levels in ${ }^{58} \mathrm{Fe}$ were included and combined as 14 sections (MT numbers) as shown in Table 1. Corresponding gamma-ray production data (file 12) and covariance data (file 33) were also provided.

These cross sections were ignored in the ENDF/B-V file for natural iron because of their low abundances: $2.1 \%$ for ${ }^{57} \mathrm{Fe}$ and $0.3 \%$ for ${ }^{58} \mathrm{Fe}$. However, for analyses ${ }^{20,21}$ of shields or critical assemblies in which iron is the dominant component, the contribution of the low-lying levels of the minor iron isolopes to neutron slowing-down is important. This is mainly because ${ }^{57} \mathrm{Fe}$ is an old isotope whose levels are dense. In particular, its first four existed levels are below $846 \mathrm{keV}$ which is the energy of the first excited state of ${ }^{56} \mathrm{Fe}$. It is therefore apparent that the low-lying levels of ${ }^{57} \mathrm{Fe}$ cannot be ignored for slowing down of neutrons below $846 \mathrm{keV}$ if there are little or no other materials in the system that have levels comparable in energy to those of ${ }^{57} \mathrm{Fe}$.

Sensitivity calculations by Kawai et al. ${ }^{20}$ for the inelastic scattering cross sections of ${ }^{57} \mathrm{Fe}$ and ${ }^{58} \mathrm{Fe}$ were performed with a central source for a 100 -cm-diam iron sphere. It was shown that a neutron flux below $10 \mathrm{keV}$ at $30 \mathrm{~cm}$ from a $0.65-\mathrm{MeV}$ source increased $60 \%$ after including the cross sections for inelastic scattering to the low-lying levels of ${ }^{57} \mathrm{Fe}$ and ${ }^{58} \mathrm{Fe}$ in the ENDF/B-IV file. Even for a 14-MeV source the increase still amounts to $20 \%$. More recently, an analysis ${ }^{21}$ of the Argonne iron benchmark, using the ENDF/B-V iron evaluation, showed that $\mathrm{k}_{\text {eff }}$ was too low by about $0.7 \%$. After incorporating calculated cross sections for inelastic scattering to the 12 lowest levels of ${ }^{57} \mathrm{Fe}$ into the file, a repeat calculation raised $\mathrm{k}_{\text {eff }}$ by $0.73 \%$.

For the above reasons, an update for MAT 1326 appeared worthwhile. Since no experimental data were available, the evaluation of the needed cross sections had to be based on model calculations. Level energies, spins, and parities were taken from the Table of Isotopes. ${ }^{22}$ Optical model parameters were 
Table 1. The energy levels of the iron isotopes as grouped for the MT numbers in ENDF/B-V Mod 2

\begin{tabular}{|c|c|c|c|c|}
\hline $\begin{array}{c}\mathrm{MT} \\
(\mathrm{keV})\end{array}$ & $\begin{array}{l}\mathrm{Fe}-54 \\
(\mathrm{keV})\end{array}$ & $\begin{array}{l}\mathrm{Fe}-56 \\
(\mathrm{keV})\end{array}$ & $\begin{array}{l}\mathrm{Fe}-57 \\
(\mathrm{keV}) \\
\end{array}$ & $\begin{array}{l}\mathrm{Fe}-58 \\
(\mathrm{keV}) \\
\end{array}$ \\
\hline 51 & & & 14.4 & \\
\hline 52 & & & 137 & \\
\hline 53 & & & 367 & \\
\hline 54 & & & 707 & \\
\hline 55 & & & & 811 \\
\hline 56 & & 846 & & \\
\hline 57 & & & 1008 & \\
\hline 58 & & & $1198,1255,1357$ & \\
\hline 59 & 1408 & & & \\
\hline 60 & & & 1628,1725 & 1675 \\
\hline 61 & & & 1975,1989 & \\
\hline 62 & & 2084 & & \\
\hline 63 & & & 2117 & \\
\hline 64 & & & 2207 & \\
\hline 65 & & & 2335,2355 & \\
\hline 66 & & & $2454,2455,2506$ & \\
\hline 67 & & & 2565,2597 & \\
\hline$\left.\right|_{90} ^{68}$ & & $\left.\right|_{4505} ^{2654}$ & & \\
\hline
\end{tabular}


those found satisfactory for ${ }^{54} \mathrm{Fe}$ and ${ }^{56} \mathrm{Fe}$ by Arthur and Young. ${ }^{23}$ Level density parameters were based on the formalism of Gilbert and Cameron. ${ }^{24}$ The TNGl code ${ }^{9}$ was used for the calculation. The code was based on the Hauser-Feshbach formalism with a consistent treatment of width-fluctuation corrections for the discrete levels and the continuum. A similar calculation for the lowest 12 levels of ${ }^{57} \mathrm{Fe}$ had been done by Smith. ${ }^{21}$ There is a general agreement between the two calculations.

Gamma-ray production cross sections for $\mathrm{E}_{n}<2.122 \mathrm{MeV}$ were based on the branching ratios given in the Table of Isotopes. ${ }^{22}$ Some branching ratios were combined, particularly those for the lumped levels. Some weak gamma rays of similar energies were also combined. For $\mathrm{E}_{n}>2.122 \mathrm{MeV}$, gamma-

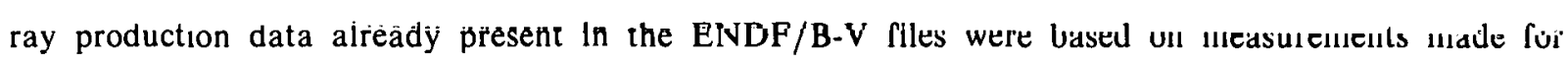
natural iron, therefore containing the pertinent information for the minor isotopes.

Since all inelastic scattering cross sections for ${ }^{57} \mathrm{Fe}$ and ${ }^{58} \mathrm{Fe}$ were based on calculation, they were assumed to be fully correlated among the levels and for all energies with an estimated standard deviation of $20 \%$.

\subsection{IMPROVED CROSS SECTIONS}

The $(n, 2 n),(n, d),(n, t)$, and $\left(n,{ }^{3} \mathrm{He}\right)$ cross sections evaluated by Arthur and Young ${ }^{2 s}$ were judged to be superior to the ENDF/B-V evaluation and were adopted. New data for $(n, 2 n)$ and $(n, d)$ were used in their evaluation. ${ }^{23}$ The corresponding covariance data in file 33 were slightly adjusted to reflect the improved knowledge of these cross sections.

\subsection{ENERGY BALANCE AND GAMMA-RAY PRODUCTION}

Energy imbalances reported by MacFarlane ${ }^{25}$ were corrected for $\mathrm{E}_{n}$ between 2.122 and $20 \mathrm{MeV}$ by adjusting the total gamma-ray production cross sections in file 13 to reproduce the estimated values of heating per collision. The adjusted results approach those of ENDF/B-IV. The largest changes occurred for $E_{n}$ between 12 and $20 \mathrm{MeV}$. The justification for the adjustment and acceptability of the results is discussed below.

When evaluating the gamma-ray production cross sections for ENDF/B-IV, ${ }^{26}$ there were two major sets of data available: one by Orphan et al. ${ }^{27}$ and one by Dickens et al. ${ }^{28}$ using ORELA. Their total 
gamma-ray production cross sections for $\mathrm{E}_{\gamma}>0.68 \mathrm{MeV}$ are shown in Fig. 4. The two data sets diverge above $5 \mathrm{MeV}$, differing by as much as a factor of two near $14 \mathrm{MeV}$. Our calculated results are in good agreement with Orphan et al. below $12 \mathrm{MeV}$ and approach the results of Dickens et al. near $14 \mathrm{MeV}$. However, our calculated energy distributions agree with Dickens et al. at all energies. Therefore, our calculated total gamma-ray production cross sections were adopted for ENDF/B-IV while using the energy distributions of Dickens et al. The total gamma-ray production cross sections for $\mathrm{E}_{\gamma}>$ $0.68 \mathrm{MeV}$ from ENDF/B-IV are shown in Fig. 4.

To resolve the above discrepancy, Chapman et al. ${ }^{29}$ undertook a new measurement using ORELA. The raw data were reduced by two methods: pulse height unfolding and pulse height weighting. The former method yielded energy distributions but required good statistics, therefore larger neutron energy bins. Both results are shown in Fig. 4 and agree almost perfectly with those of Orphan et al. To ensure that there were no serious errors in the new measurement, Chapman et al. also made test measurements on carbon, copper, and tantalum which compared with older ORELA results. It was thought that the older measurement by Dickens et al. had some unknown errors and should be superceded by the new measurement. Therefore, we adopted the new measurement for ENDF/B-V.

Recently a consistent calculation of neutron production and gamma-ray production cross sections by Arthur and Young ${ }^{23}$ suggested problems in the data of Chapman et al. near $14 \mathrm{MeV}$. Their calculation at $14 \mathrm{MeV}$ agrees better with ENDF/B-IV than with ENDF/B-V. In addition, the gamma-ray production cross section measured by Drake et al. ${ }^{14}$ at an incident neutron energy of $14.2 \mathrm{MeV}$ is closer to that of Dickens et al. than to Chapman et al. At the same time, energy imbalances in the ENDF/B-V iron evaluation were revealed by MacFarlane. ${ }^{25}$ Both problems are discussed below.

A detailed calculation was made for the heating per collision using the new evaluated file that has the changes proposed above incorporated into it. The results are shown in Table 2 for some representative energies along with the values derived from our model calculations. The latter values may be good to $20 \%$. The former values are substantially lower than the latter and some are negative, particularly near $14 \mathrm{MeV}$. It is apparent that the specific energies for either or both the outgoing neutrons and outgoing gamma rays need to be reduced. The specific energy is the energy of the outgoing particle times 
ORNL-DWG $82-9817$

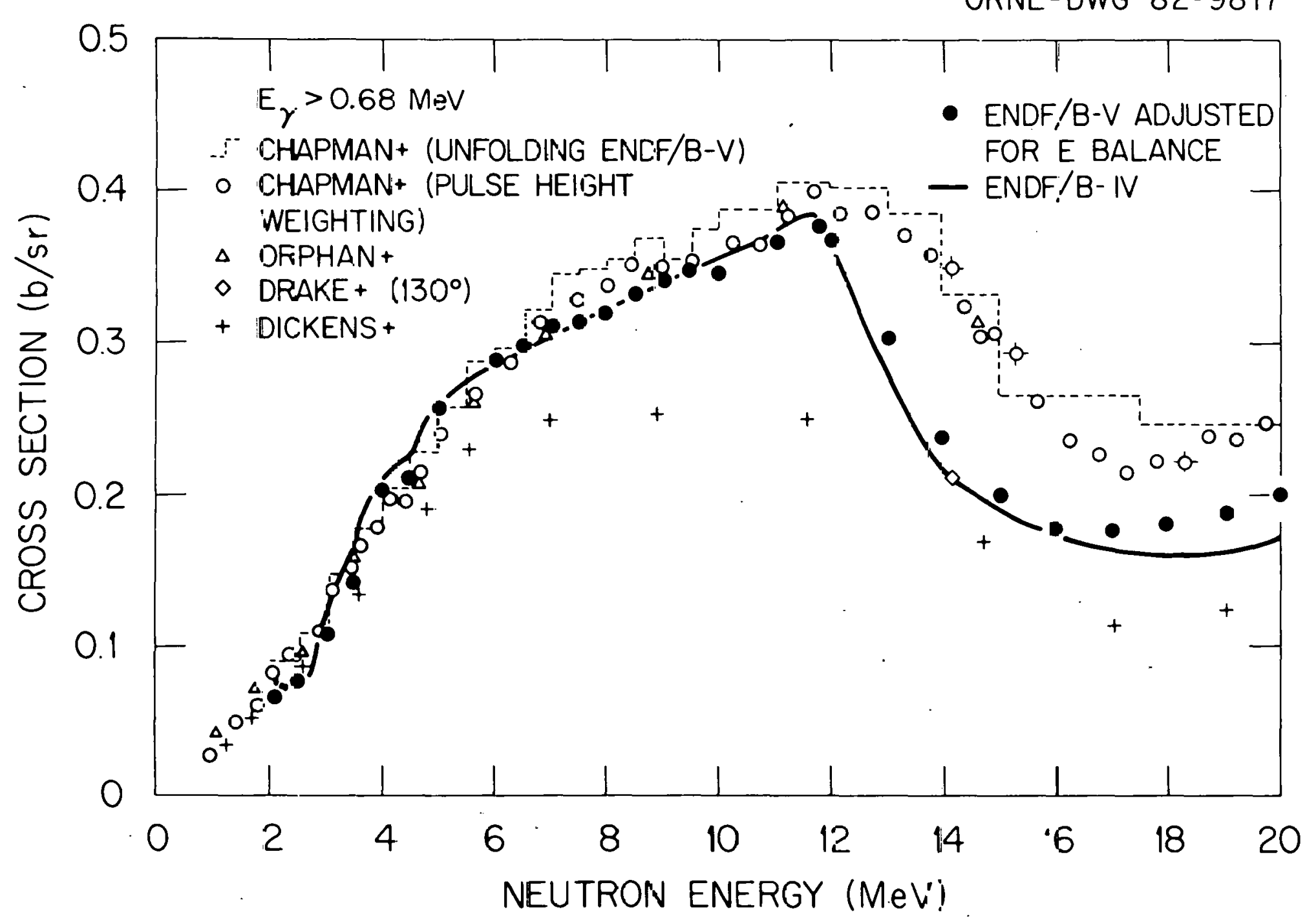

Fig. 4. Varicus experimental and evaluated gamma-ray production cross sections for natural iron. 
Table 2. Some typical heating values calculated from the modified ENDF/B-V $\left(\mathbf{H}_{5}\right)$, from model calculations $\left(\mathbf{H}_{c}\right)$, and the necessary adjustments in gamma-ray production cross sections

\begin{tabular}{cccc}
\hline $\begin{array}{c}\mathrm{E}_{n} \\
(\mathrm{MeV})\end{array}$ & $\begin{array}{c}\mathrm{H}_{5} \\
(\mathrm{MeV})\end{array}$ & $\begin{array}{c}\mathrm{H}_{c} \\
(\mathrm{MeV})\end{array}$ & $\begin{array}{c}\Delta \mathrm{G}_{\gamma} \\
(\mathrm{mb})\end{array}$ \\
\hline 3 & -0.075 & 0.063 & -426 \\
5 & 0.087 & 0.117 & -76 \\
7 & -0.019 & 0.194 & -440 \\
9 & 0.13 & 0.301 & -280 \\
11 & -0.003 & 0.44 & -588 \\
14 & -0.463 & 0.70 & -1335 \\
17 & 0.46 & 1.03 & -1353 \\
\hline
\end{tabular}

its production cross section. Examining all the available data, we found little room for changing either the neutron production cross sections, the secondary neutron energy distributions, or the secondary gamma-ray cnergy distributions. But as is evident from Fig. 4, there is some flexibility in reducing the gamma-ray production cross sections. Therefore, we adjusted the total gamma-ray-production cross sections to reproduce the more desirable heating values derived from our model calculations. The adjusted results, also shown in Fig. 4 for $E_{\gamma}>0.68 \mathrm{MeV}$, approach those used in ENDF/B-IV and represent a compromise of all experimental data. The results also agree with the Arthur and Young evaluation. ${ }^{23}$

The total gammi-ray production cross sections in ENDF/B-V was replaced with the adjusted results as a plausible solution to the energy imbalance problem for $E_{n}>2.122 \mathrm{MeV}$.

For $\mathrm{E}_{n}<2.122 \mathrm{MeV}$, energy imbalances still exist. Here the gamma rays produced are from inelastic scattering and radiative capture. The problem was due to the neutron-energy-dependent capture 
gamma-ray spectra given in the file. For each neutron group, the gamma rays produced may be representative of just one isotope, having its own unique Q-value. Therefore, a single Q-value, as required by the ENDF/B-V formats, cannot adequately define the energy balance. This is the wellknown "elemental Q-value problem," but solutions other than providing isotopic evaluations are still wanting.

\subsection{RESONANCE PARAMETERS}

Resonance parameters (file 2) and covariances (file 32) were revised so that the files and the corresponding report ${ }^{6}$ are consistent. A few clerical errors were also corrected. However, changes were either very small or involved insignificant resonances. 


\section{UPDATES FOR COPPER (ENDF/B-V MAT 1329)}

Recent high-quality production cross sections of protons and alpha particles near $14 \mathrm{MeV}$, together with advances in nuclear model codes, have made possible drastic improvement over ENDF/B-IV ${ }^{31}$ in these cross sections. ${ }^{32}$ The $(n, p)$ cross section near $14 \mathrm{MeV}$, for example, was reduced by a factor of three. Improvements were also made in some total cross sections and some capture gamma-ray spectra.

\section{1 (n,p) AND PROTON PRODUCTION CROSS SECTIONS}

The proton production cross section for $E_{n}<20 \mathrm{MeV}$ in copper is the sum of $(n, p)$, (n,pn), and $(n, n p)$ cross sections, or the sum of MT28 and MT103 in terms of the ENDF/B-V formats. Here MT28 represents the sum of the $(n, n p)$ and $(n, p n)$ cross sections and, strictly speaking, is incorrectly called the $(n, n p)$ cross section.

These cross sections were evaluated separately for each isotope. There was essentially no ${ }^{63} \mathrm{Cu}(\mathrm{n}, \mathrm{p})$ measurement for the ENDF/B-IV evaluation. The two data points ${ }^{32,33}$ near $14 \mathrm{MeV}$ quoted in BNL325 (ref. 16) as (n,p) were actually (n,px), thus including a large component for (n,pn). Apparently the ENDF/B-IV evaluators took these values as $(n, p)$ and normalized their calculated curve to the average of these two values. This resulted in an evaluated ${ }^{63} \mathrm{Cu}(n, p)$ cross section at $14 \mathrm{MeV}$ that was a factor of five larger than what was determined below.

Because proton distrihutions for the two measurements cited above were not available, it was not possible to extract the $(n, p)$ cross section from the (n,px) cross section. Fortunately, a recent Lawrence Livermore National Laboratory (LLNL) measurement by Grimes et al. ${ }^{34}$ for the proton production cross section at $14.8 \mathrm{MeV}$ provides detailed proton distributions. These distributions, coupled with advanced model analysis, yielded separate cross sections for the (n,p), (n,pn), and (n,np) reactions as shown in Fig. 5. The details of the calculation (multi-step Hauser-Feshbach with precompound effects) have been documented. ${ }^{9}$ The calculated excitation functions shown in Fig. 6 were adopted for ${ }^{63} \mathrm{Cu}$.

The ${ }^{63} \mathrm{Cu}(\mathrm{n}, \mathrm{np})$ cross section at $14 \mathrm{MeV}$ obtained above was $165 \mathrm{mb}$ and was in good agreement with the average of four data points quoted in BNL-325 (ref. 16) which was $170 \mathrm{mb}$. Note that the $(n, n p)$ cross section is meant here instead of the sum of the $(n, n p)$ and $(n, p n)$ cross sections. 


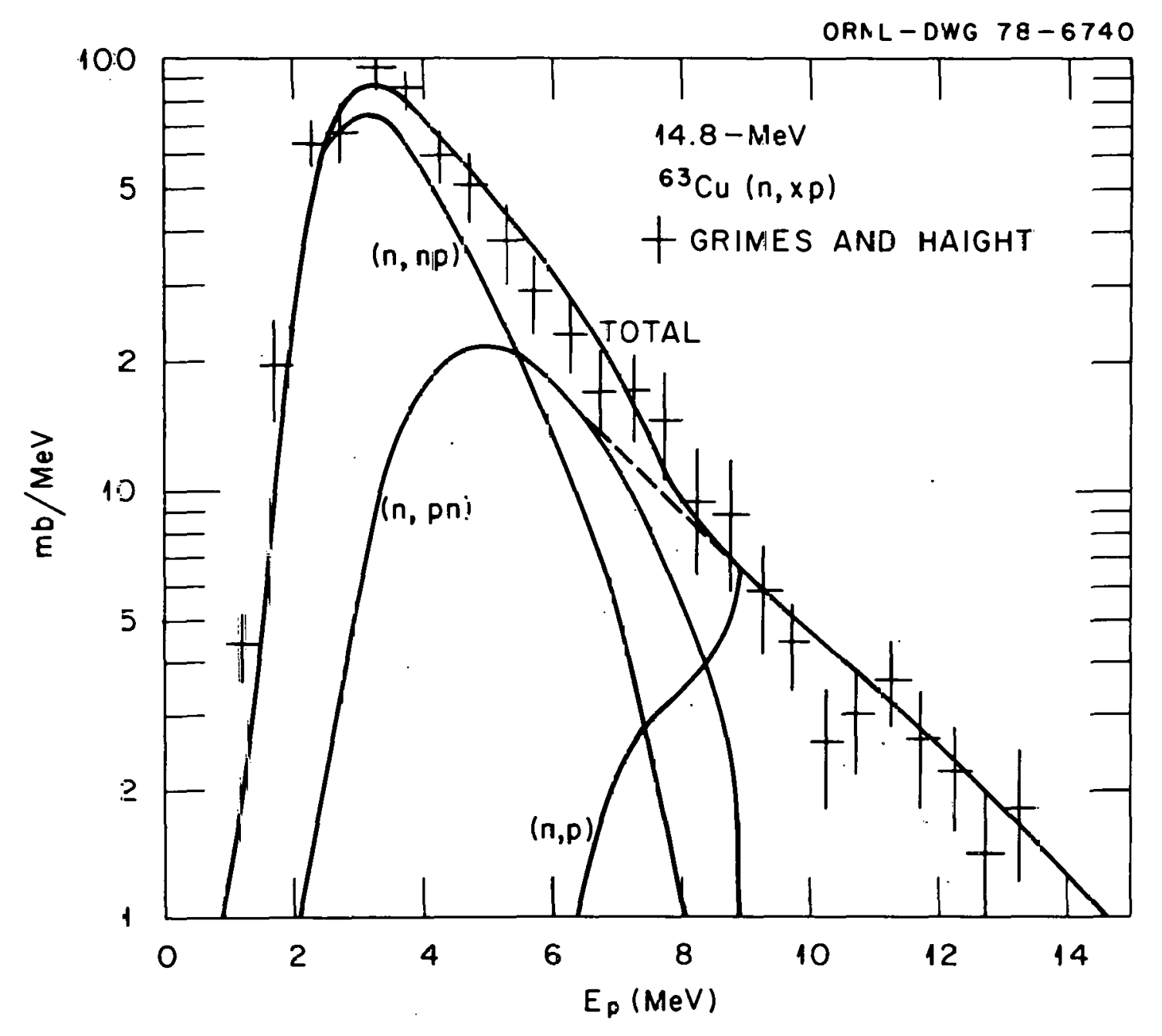

Fia 5 A model analysis of the measured proton spectrum to extract $14.8-\mathrm{MeV}{ }^{63} \mathrm{Cu}(\mathrm{n}, \mathrm{p}),(\mathrm{n}, \mathrm{pn})$,

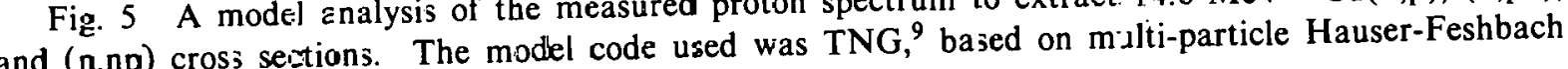
and precompound theories. 


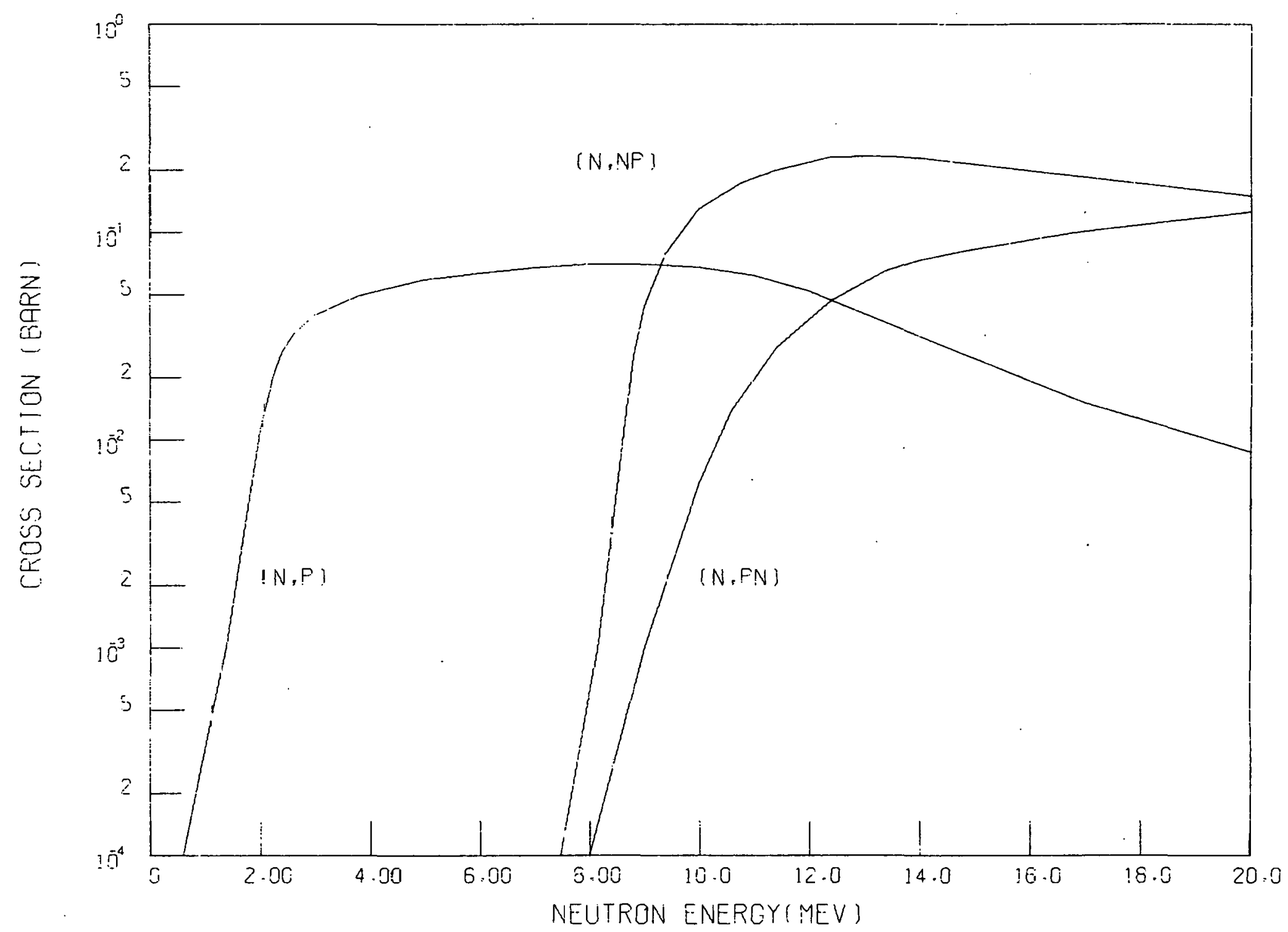


For the ${ }^{65} \mathrm{Cu}(\mathrm{n}, \mathrm{p})$ cross section, the previous evaluation was adopted. ${ }^{31}$ The available data remained unchanged but appeared adequate to define the entire excitation function. For ${ }^{65} \mathrm{Cu}(\mathrm{n}, \mathrm{np})$, the calculated results by Mann and Schenter ${ }^{35}$ were adopted, but the cross sections above $12 \mathrm{MeV}$ (20\% at 20 $\mathrm{MeV}$ ) were reduced to obtain agreement with the LLNL proton production cross section at $14.8 \mathrm{MeV}$. These results are shown in Fig. 7.

The cross-section values for the above reactions obtained for ${ }^{63} \mathrm{Cu}$ and ${ }^{65} \mathrm{Cu}$, with abundances of $69.2 \%$ and $30.8 \%$ respectively, were combined for natural copper. The results are shown in Figs. 8 and 9 together with the ENDF/B-IV values.

\section{$5.2(n, \alpha)$ AND THE ALPHA-PARTICLE PRODUCTION CROSS SECTIONS}

The alpha-particle production cross section below $20 \mathrm{MeV}$ in copper is the sum of $(n, \alpha),(n, n \alpha)$, and $(n, \alpha n)$ cross sections, or the sum of MT22 and MT107 in terms of the ENDF/B terminology. Here MT22 is the sum of $(n, n \alpha)$ and $(n, \alpha n)$ cross sections.

Two high-quality measurements for the alpha production cross section at $14.8 \mathrm{MeV}$ have been made since the ENDF/B-IV evaluation. The LLNL measurements by Grimes et al. ${ }^{34}$ were for ${ }^{63} \mathrm{Cu}$ and

${ }^{65} \mathrm{Cu}$; the Rockwell measurement by Farrar and Kneff ${ }^{35}$ was for natural copper. A weighted average of the LLNL data yielded $43 \pm 7 \mathrm{mb}$ for natural copper. The Rockwell value is $51 \pm 3 \mathrm{mb}$. The aver* age of the two values is $49 \pm 2 \mathrm{mb}$. Weighing the original LLNL values for the isotopes by the last average, $64 \mathrm{mb}$ for ${ }^{63} \mathrm{Cu}$ and $15 \mathrm{mb}$ for ${ }^{65} \mathrm{Cu}$ were obtained. These values were used for normalization at $14.8 \mathrm{MeV}$ in the following manner.

The ${ }^{63} \mathrm{Cu}(\mathrm{n}, \alpha)$ cross sections ${ }^{37}$ evaluated for the ENDF/B-IV dosimetry file were adopted. The corresponding evaluation for the ENDF/B-V dosimetry file was nul available at the time. The calculated excitation function for the sum of $(n, n \alpha)$ and $(n, \alpha n)$ cross sections ${ }^{9}$ was normalized to yield the required alpha production cross section of $64 \mathrm{mb}$ at $14.8 \mathrm{MeV}$. These cross sections are shown in Fig. 10.

For ${ }^{65} \mathrm{Cu}$, the sum of $(n, n \alpha)$ and $(n, \alpha n)$ cross sections was unchanged from the earlier evaluation ${ }^{31}$ which had adequate data. For ${ }^{65} \mathrm{Cu}(\mathrm{n}, \alpha)$, the calculation by Mann and Schenter ${ }^{35}$ was used up to 12 $\mathrm{MeV}$, and their calculated curve above $12 \mathrm{MeV}$ (40\% reduction near $15 \mathrm{MeV}$ ) was reduced to obtain 


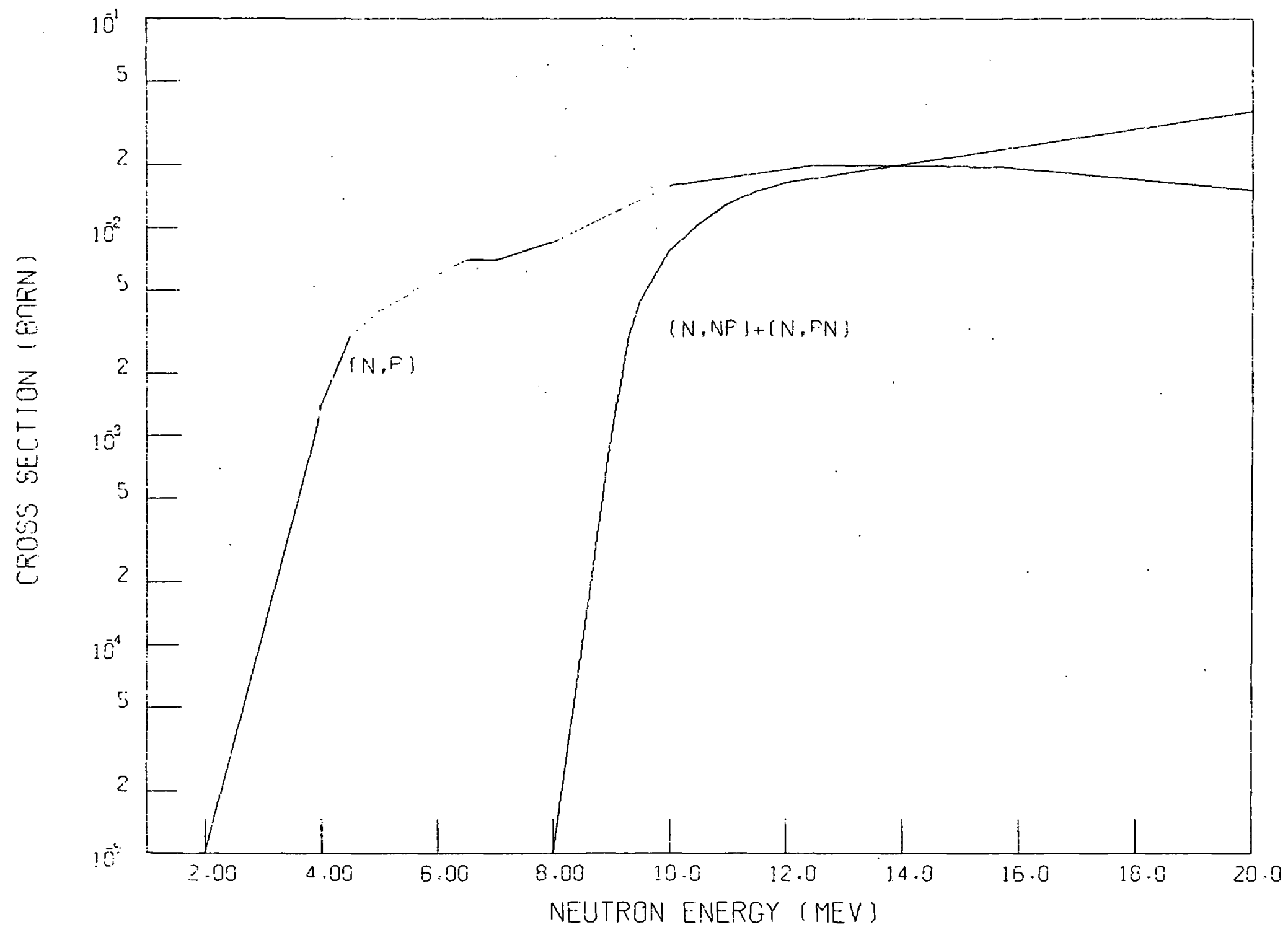

Fig. 7. Present evaluation of $(n, p),(n, p n)+(n, n p)$ cross sections for ${ }^{65} \mathrm{Cu} .{ }^{65} \mathrm{Cu}(n, p)$ cross sections were taken from the previous evaluation ${ }^{31}$ where adequate data existed. 


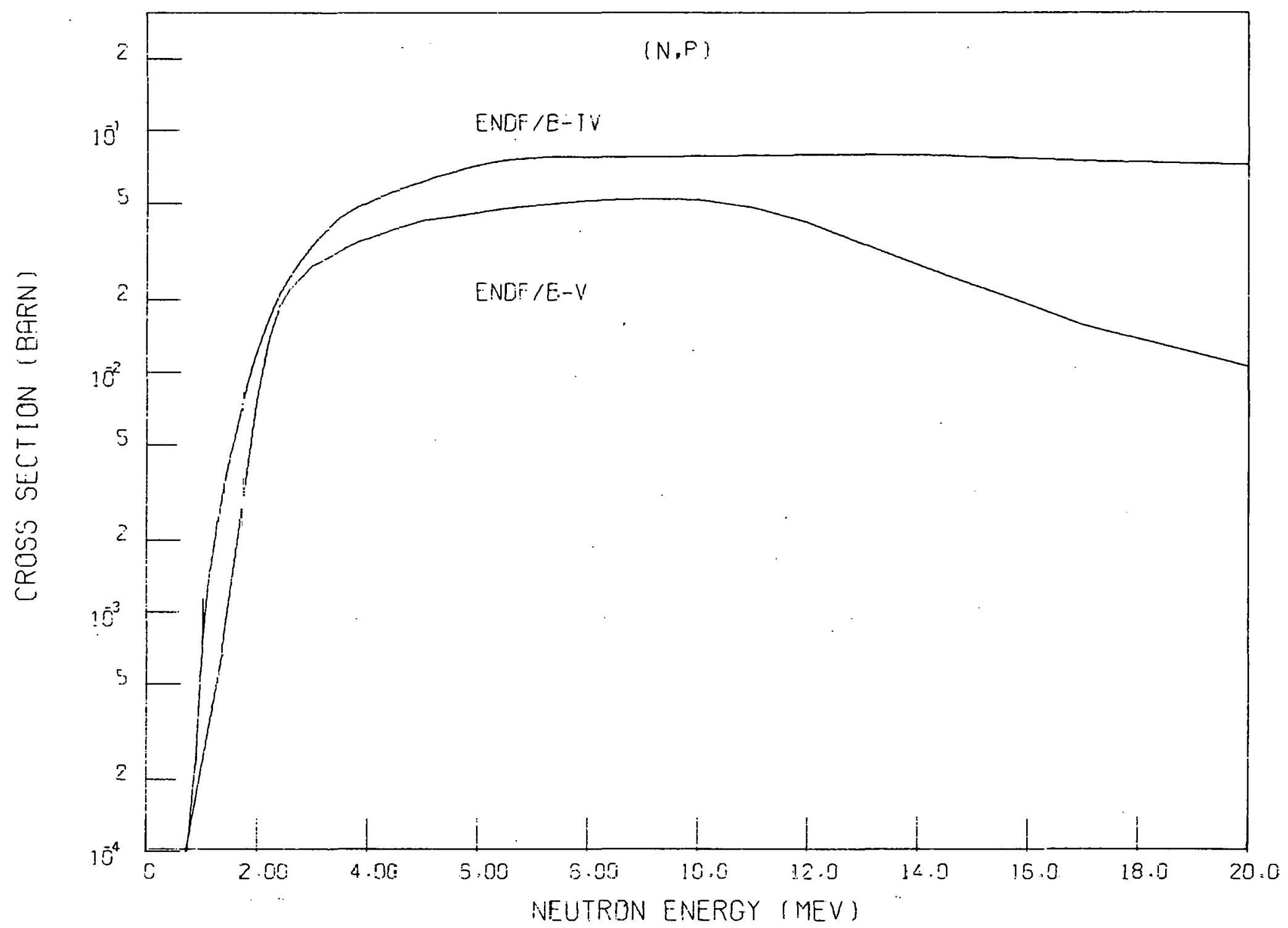

Fig. 8. Comparison of ENDF/B-V $(n, p)$ cross sections with ENDF/B-IV for natural copper. 


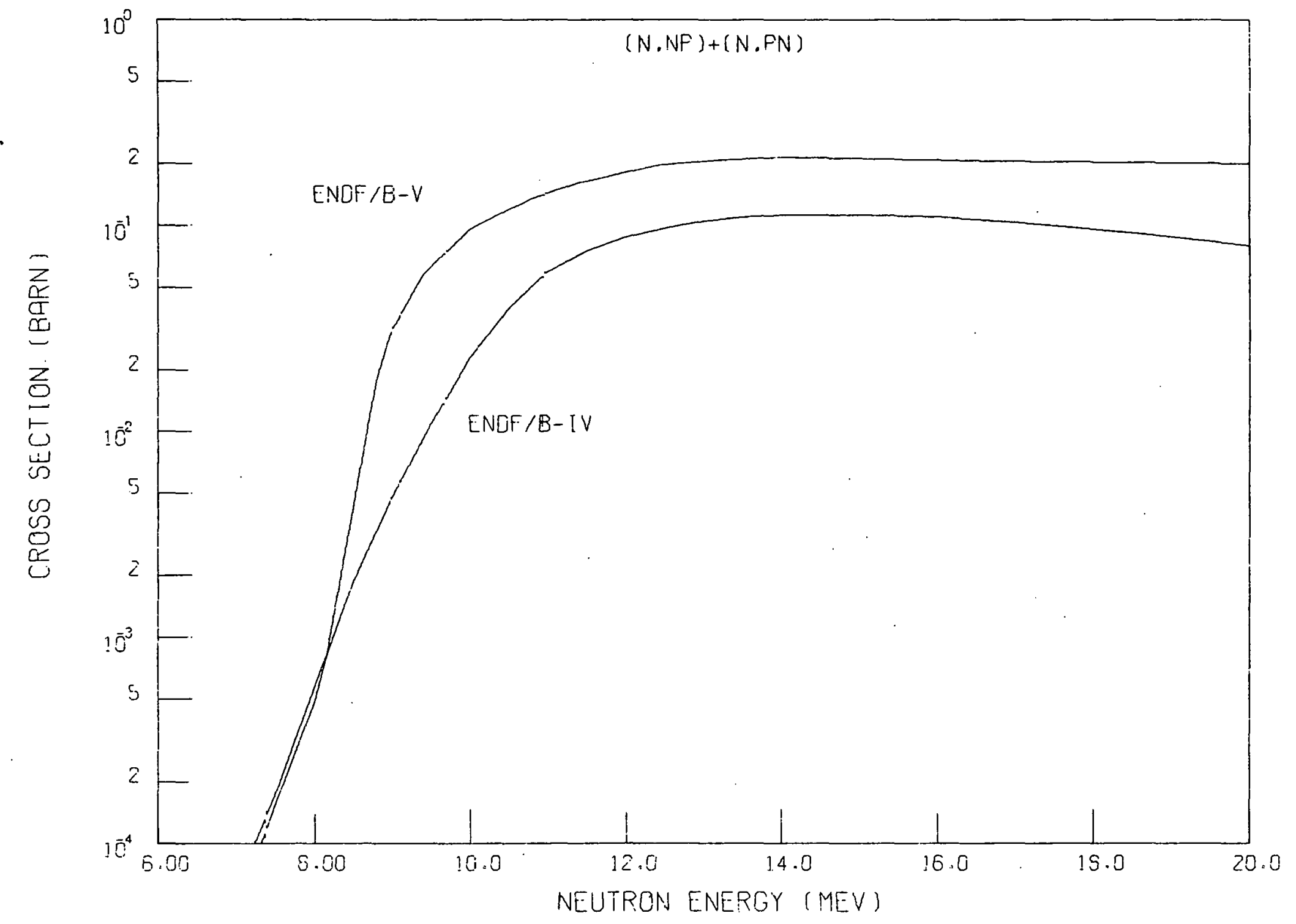
copper. 


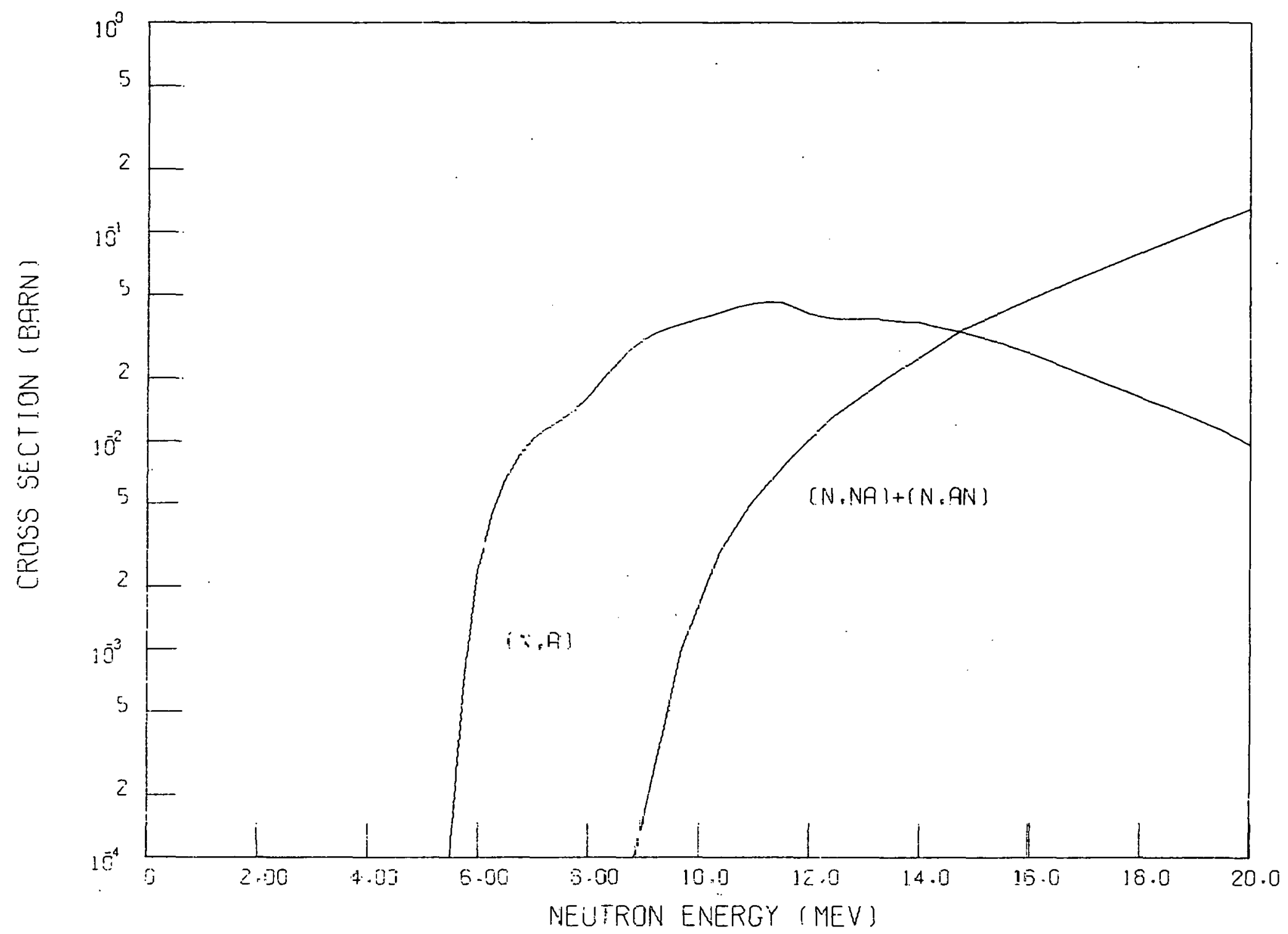

Fig. 10. Present evaluation of $(n, \alpha)$ and $(n, \alpha n)+(n, n a)$ cross sections for ${ }^{63} \mathrm{Cu} .{ }^{63} \mathrm{Cu}(\mathrm{n}, \alpha)$ cross seotions were taken from the ENDF/B-IV dosimetry file. ${ }^{37}$ 
the required 14.8- $\mathrm{MeV}$ value for the alpha production cross section. The results are shown in Fig. 11.

The results recommended for natural copper are shown in Figs. 12 and 13 together with those for ENDF/B-IV.

\subsection{TOTAL CROSS SECTIONS}

The high-resolution total cross sections from $80 \mathrm{keV}$ to $20 \mathrm{MeV}$ measured by Perey ${ }^{38}$ using the Oak Ridge Electron Linear Accelerator (ORELA) were compared with the ENDF/B-IV values and some older data. ${ }^{39-41}$ The ORELA data shown in Figs. 14 to 25 were fitted by line segments and were adopted for Version $\mathrm{V}$ because high-resolution total cross sections were needed for shielding applications. However, the agreement of the data as shown in Figs. 14 to 25 is generally poor. The ORELA data were adopted after it was observed that ORELA total cross sections for other materials which were measured similarly in the same energy range have been found to agree with high-resolution data taken elsewhere. ${ }^{1,3,10}$ From 2 to $20 \mathrm{MeV}$, there was good agreement between the ORELA data and the ENDF/B-IV values as shown in Fig. 26. In Fig. 27 the available total cross sections from $80 \mathrm{keV}$ to $200 \mathrm{keV}$ are shown. It appears there is a gap between $100 \mathrm{keV}$ and $200 \mathrm{keV}$ where high-resolution total cross sections are needed.

\subsection{CAPTURE GAMMA-RAY SPECTRA}

The gamma-ray production cross sections and spectra measured by Chapman et al. ${ }^{42}$ using ORELA for two incident neutron bins from 0.2 to $0.6 \mathrm{MeV}$ and from 0.6 to $1.25 \mathrm{MeV}$ were adopted. These were given in the evaluated file as capture gamma rays after removing the contributions from inelastic scattering as shown in Figs. 28 and 29. There were no other data available in this energy range. For higher incident neutron energies, the ORELA data and the ENDF/B-IV values appeared ${ }^{42}$ in good agreement.

\subsection{THINNING OF CAPTURE CROSS SECTIONS}

The capture cross sections in the ENDF/B-IV evaluation were thinned to $1 \%$ linearly, reducing the energy entries from 408 to 48 . This automatically shortened the files for total, elastic, and nonelastic cross sections. 


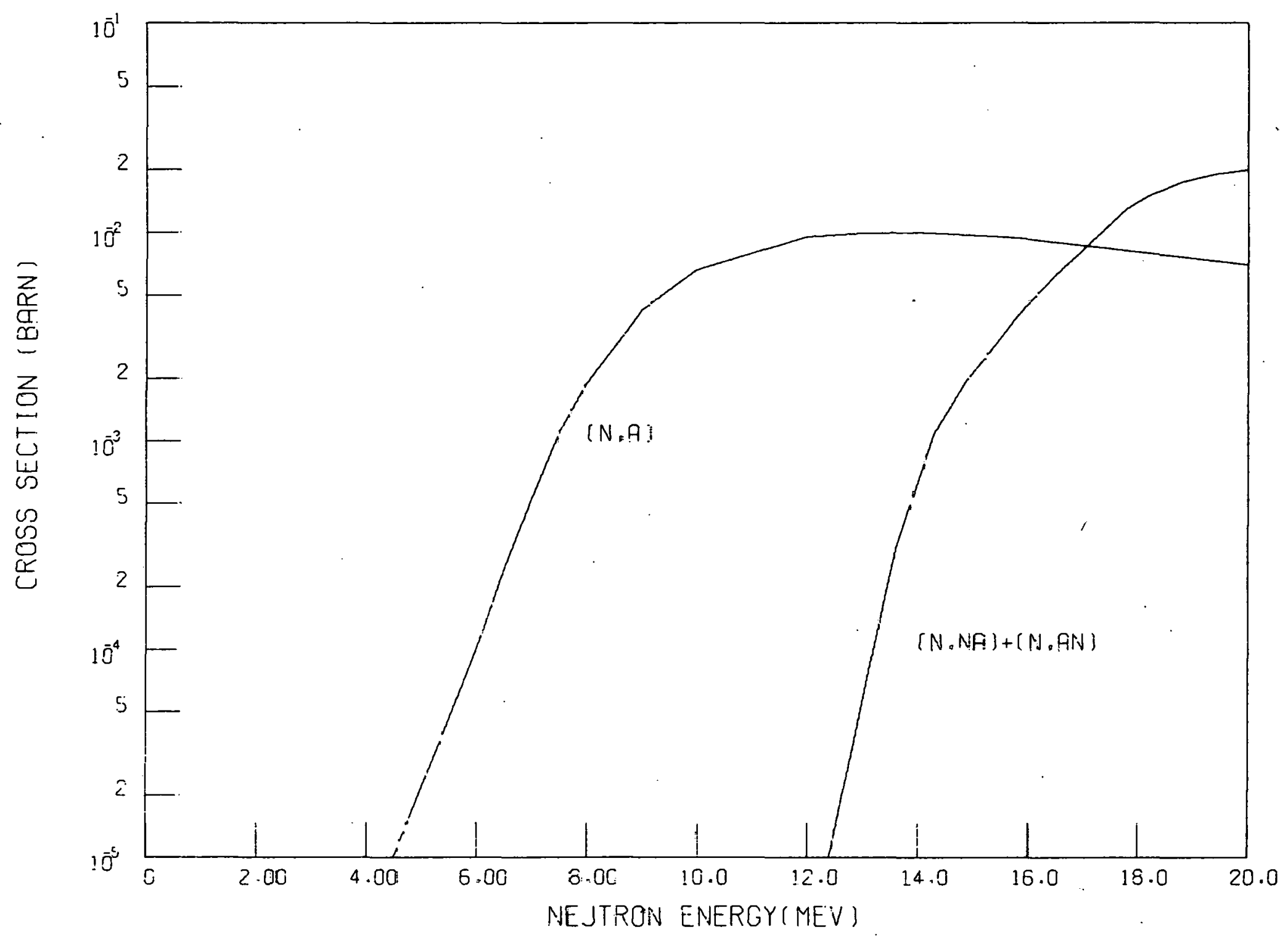

N

Fig. 11. Present evaluation of $i n, \alpha)$ and $(n, n \alpha)+(n, \alpha n)$ cross sections for ${ }^{65} \mathrm{Cu}$. 


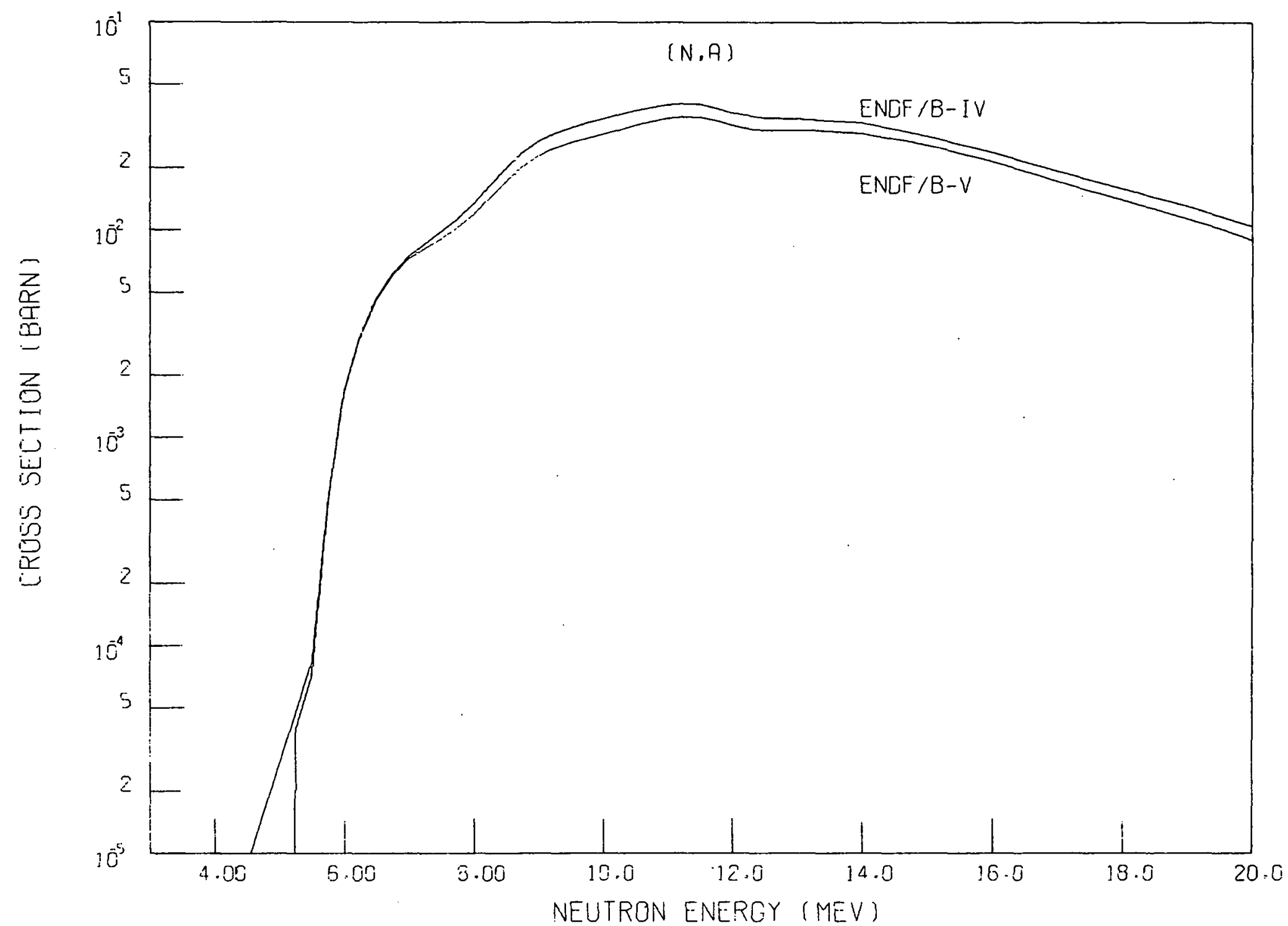

Fig. 12. Comparison of ENDF/B-V $(n, \alpha)$ cross sections with ENDF/B-IV for natural copper. 


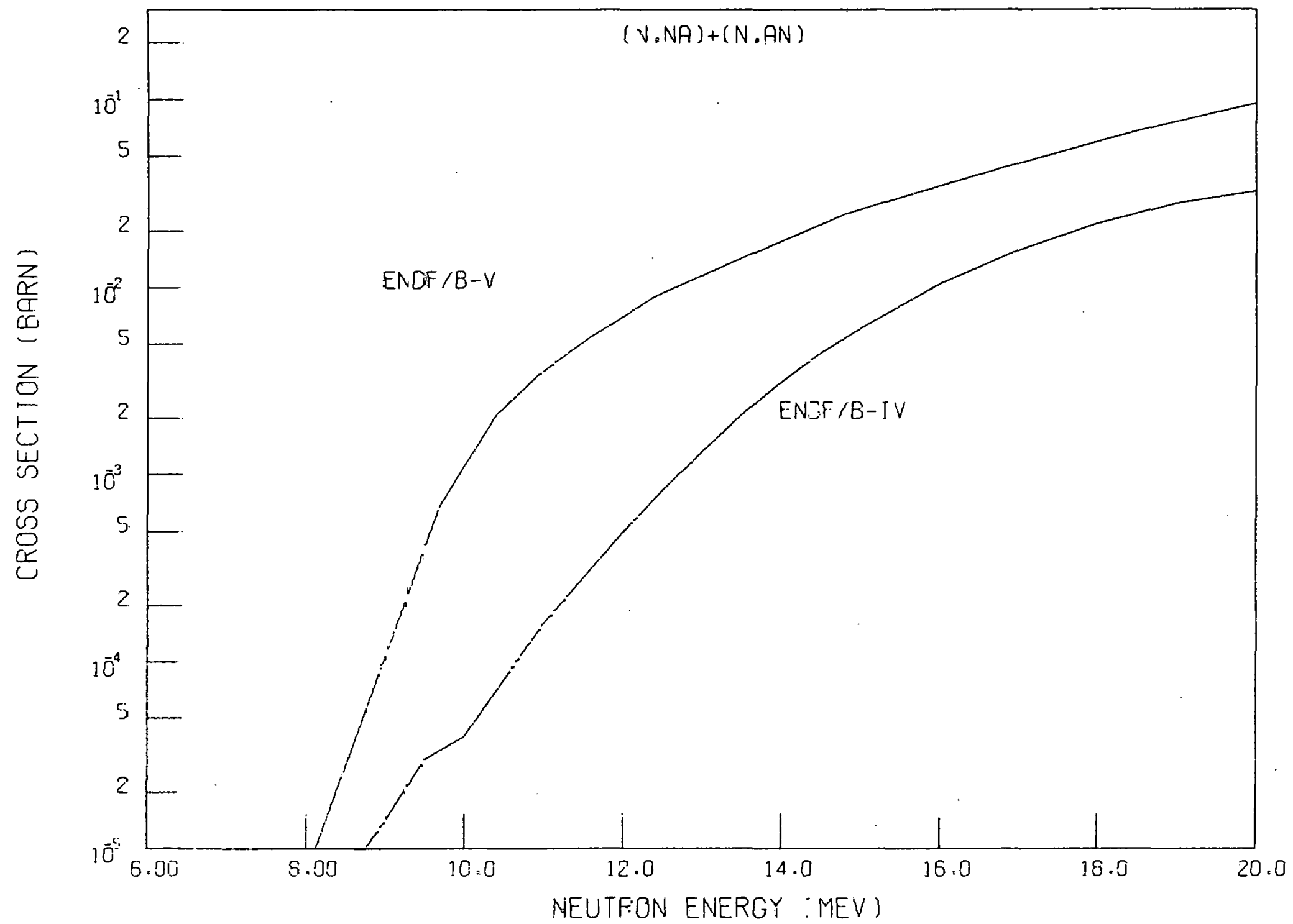




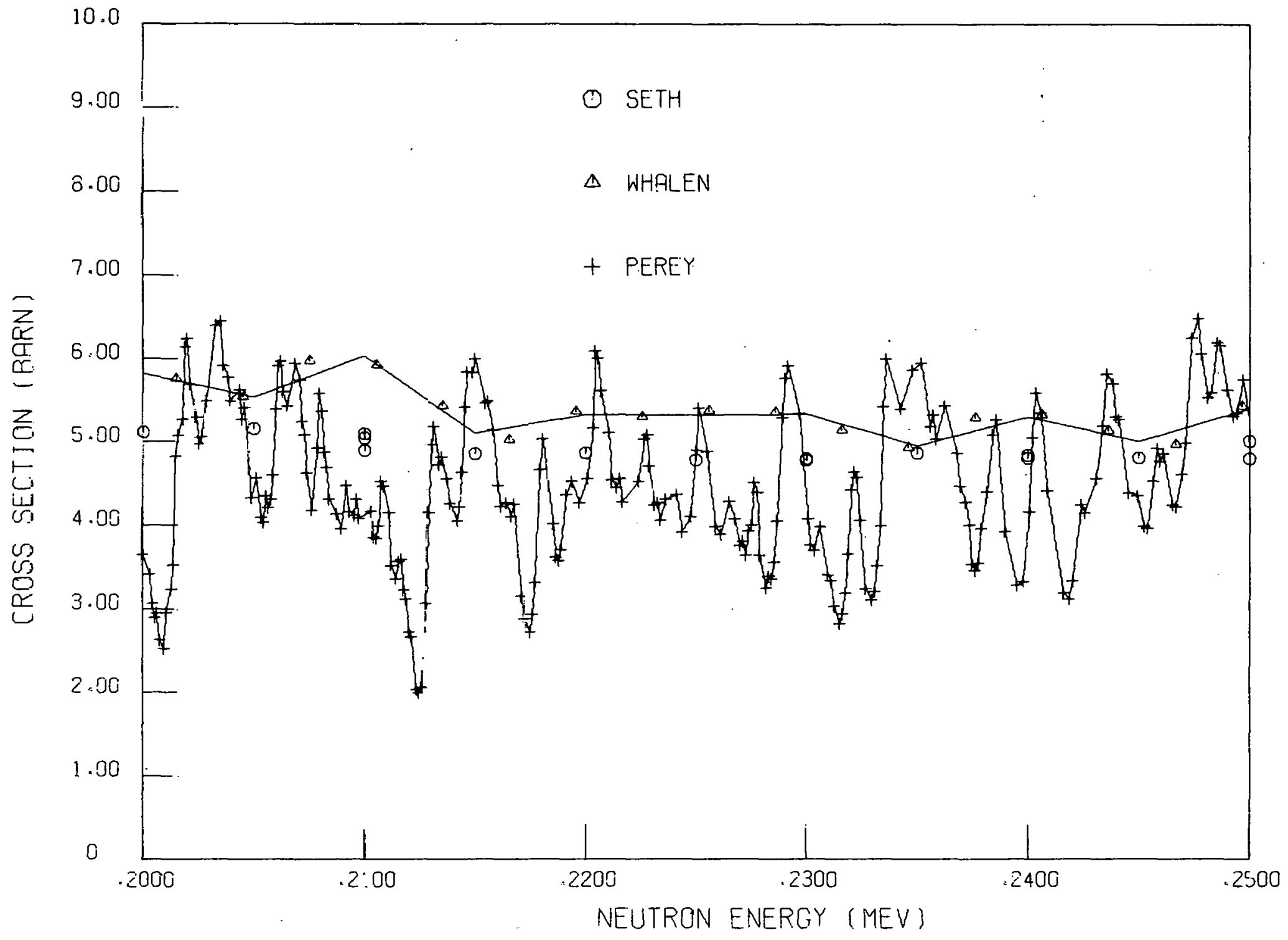




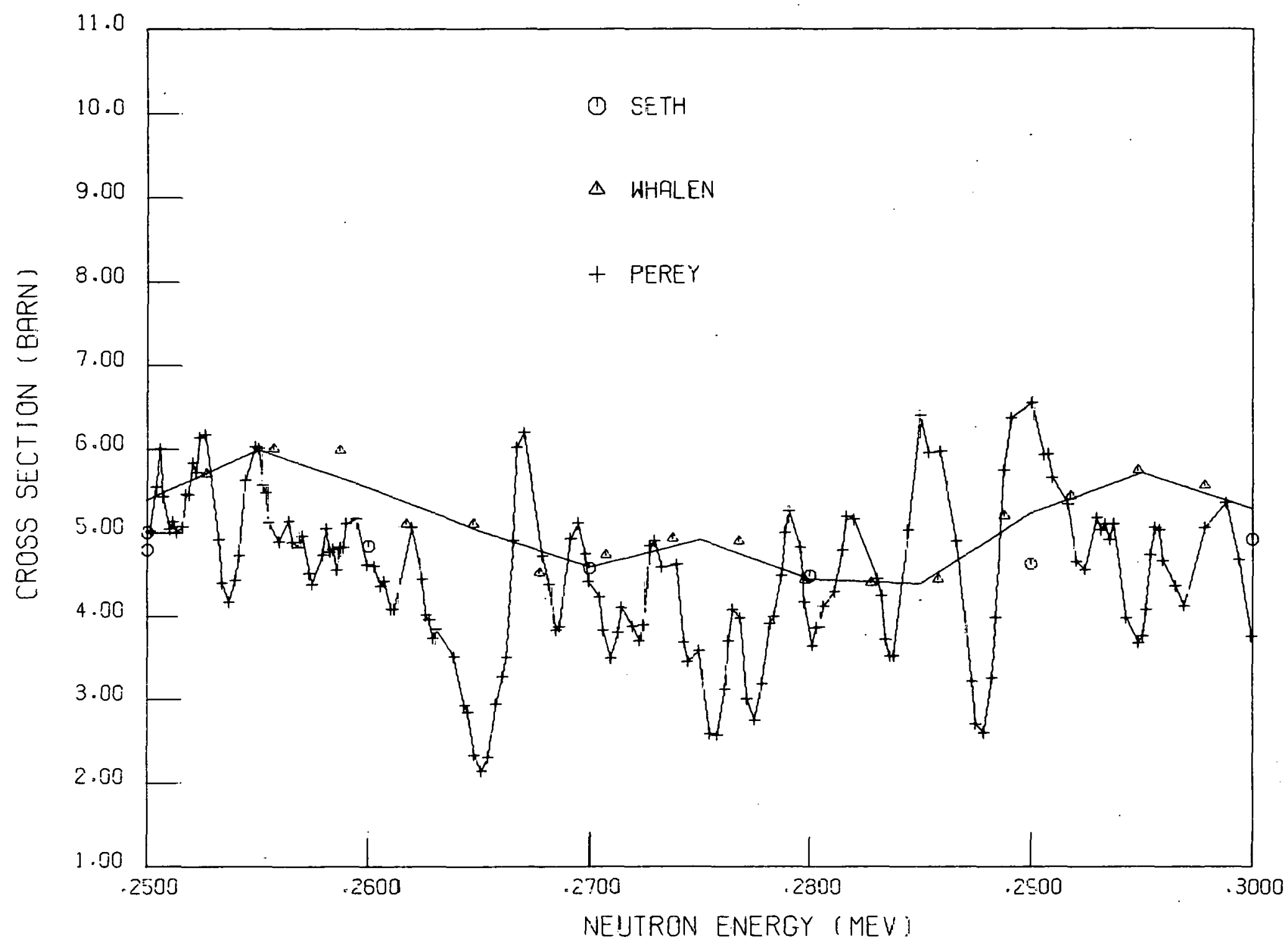



Fig. 15. Cu tolal cross sections in ENDF/E-IV and - V (Perey's data). 


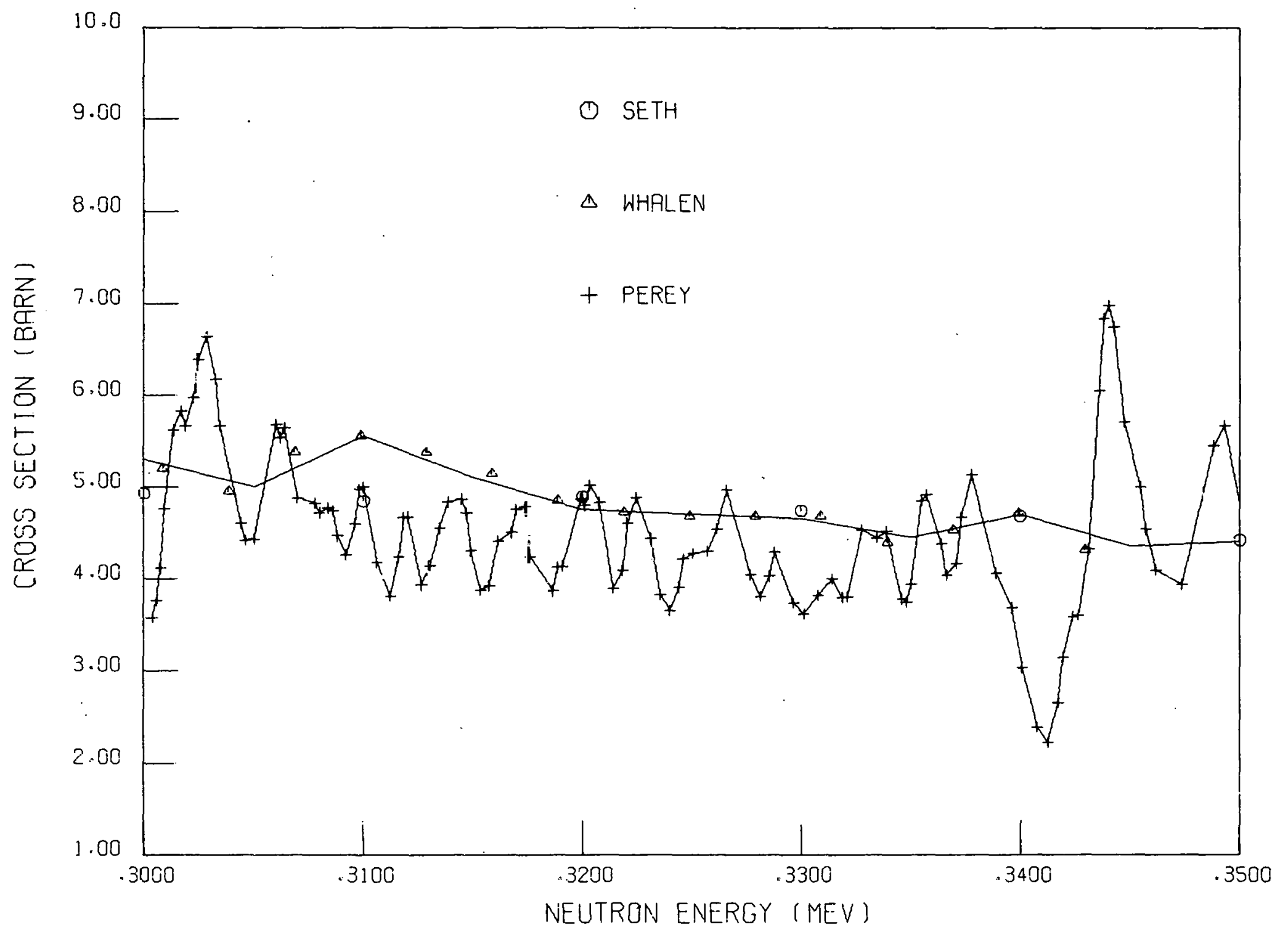




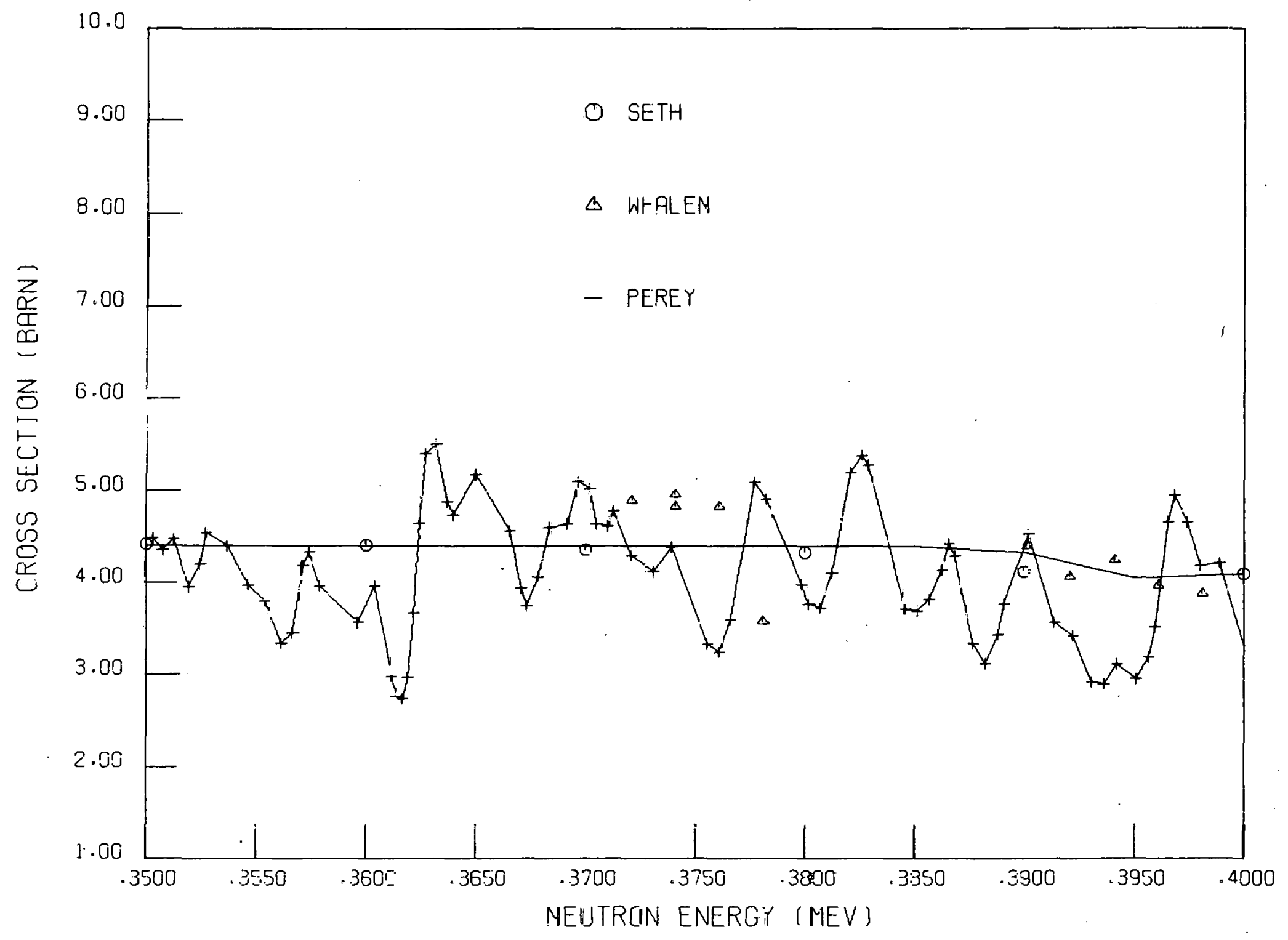




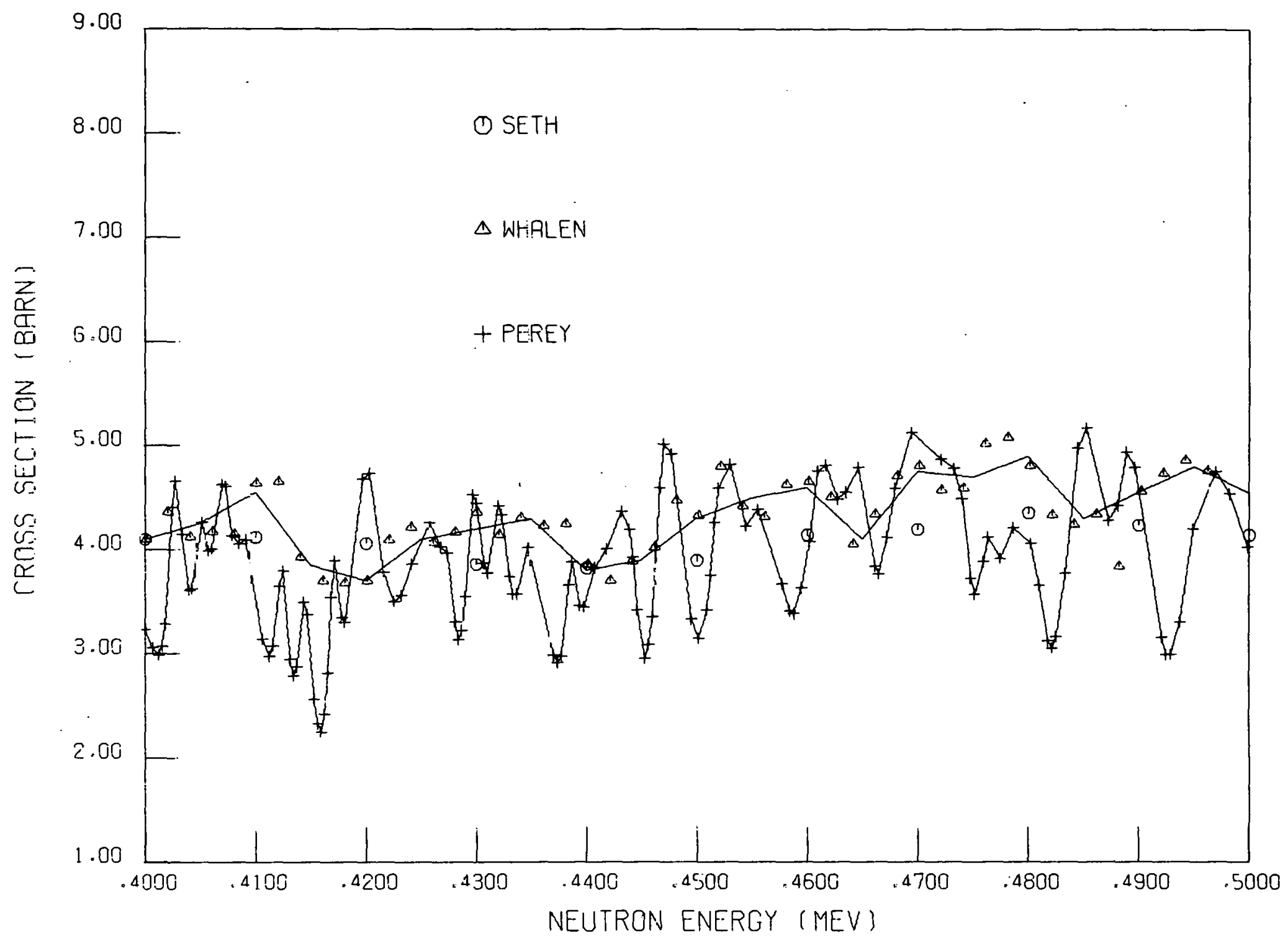

Fig. 18. Cu total cross sections in ENDF/B-IV and -V (Perey's data). 


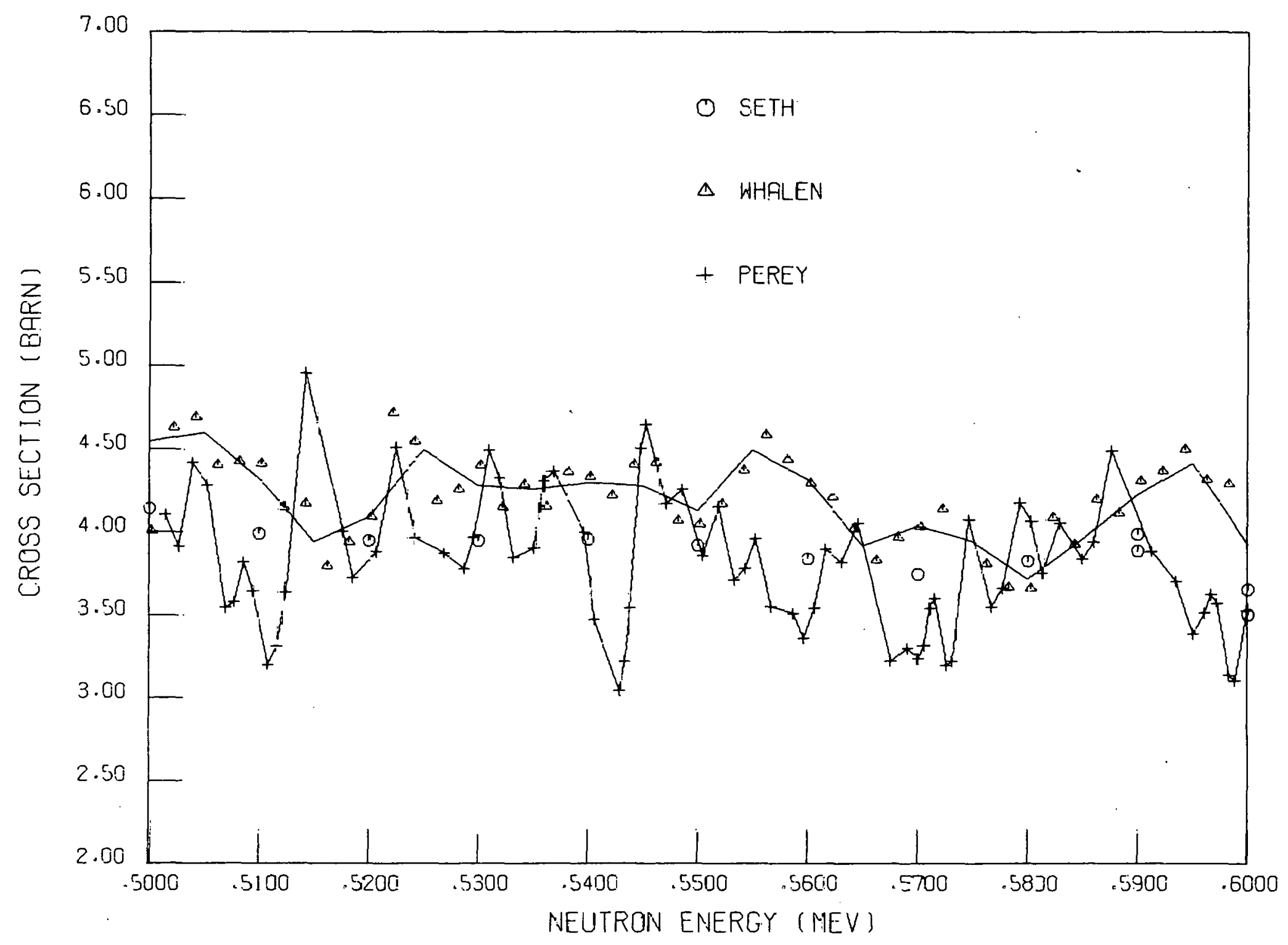

Fig. 19. Cu total cross secticns in ENDF/B-IV and -V (Perey's data). 


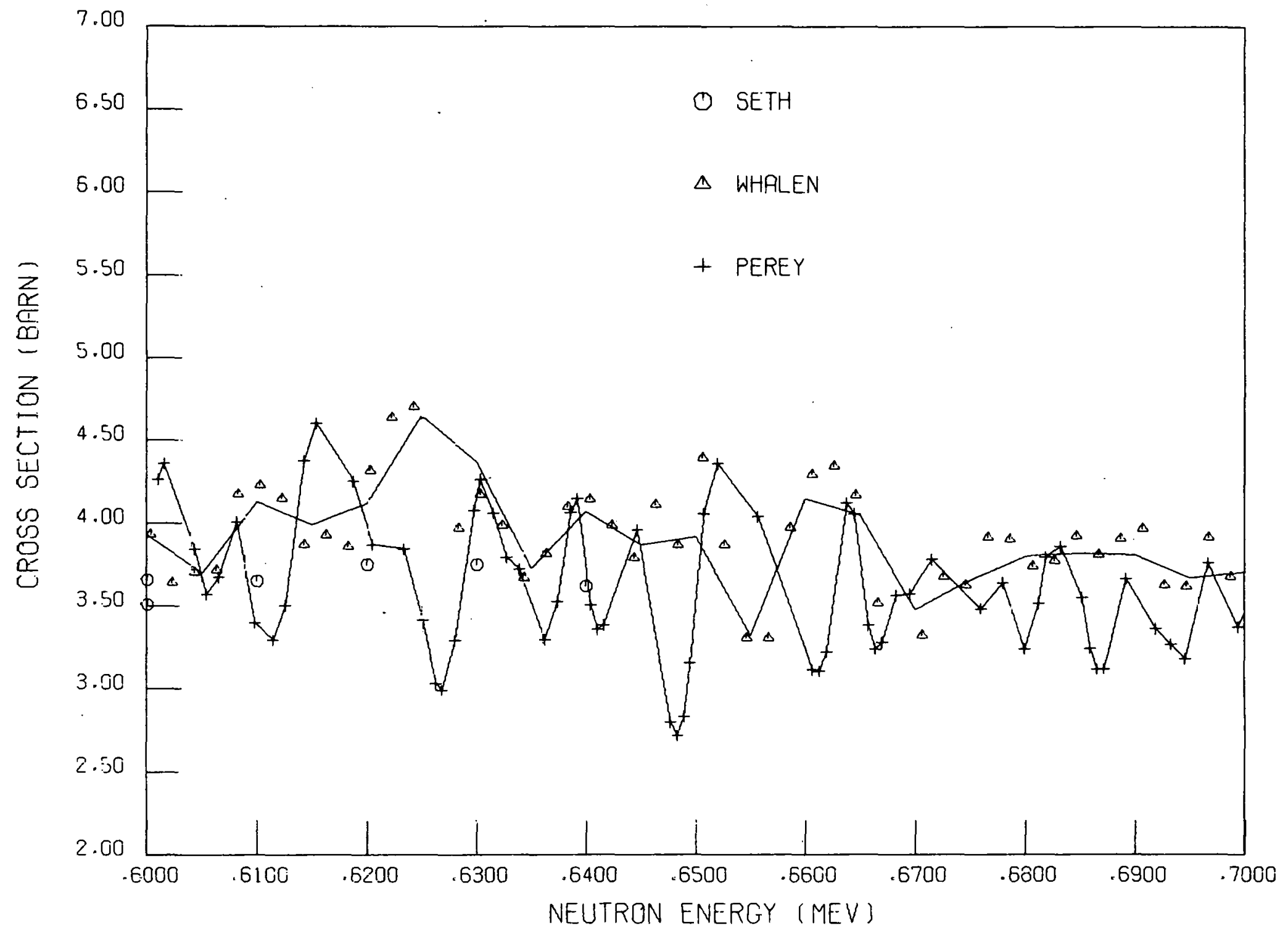




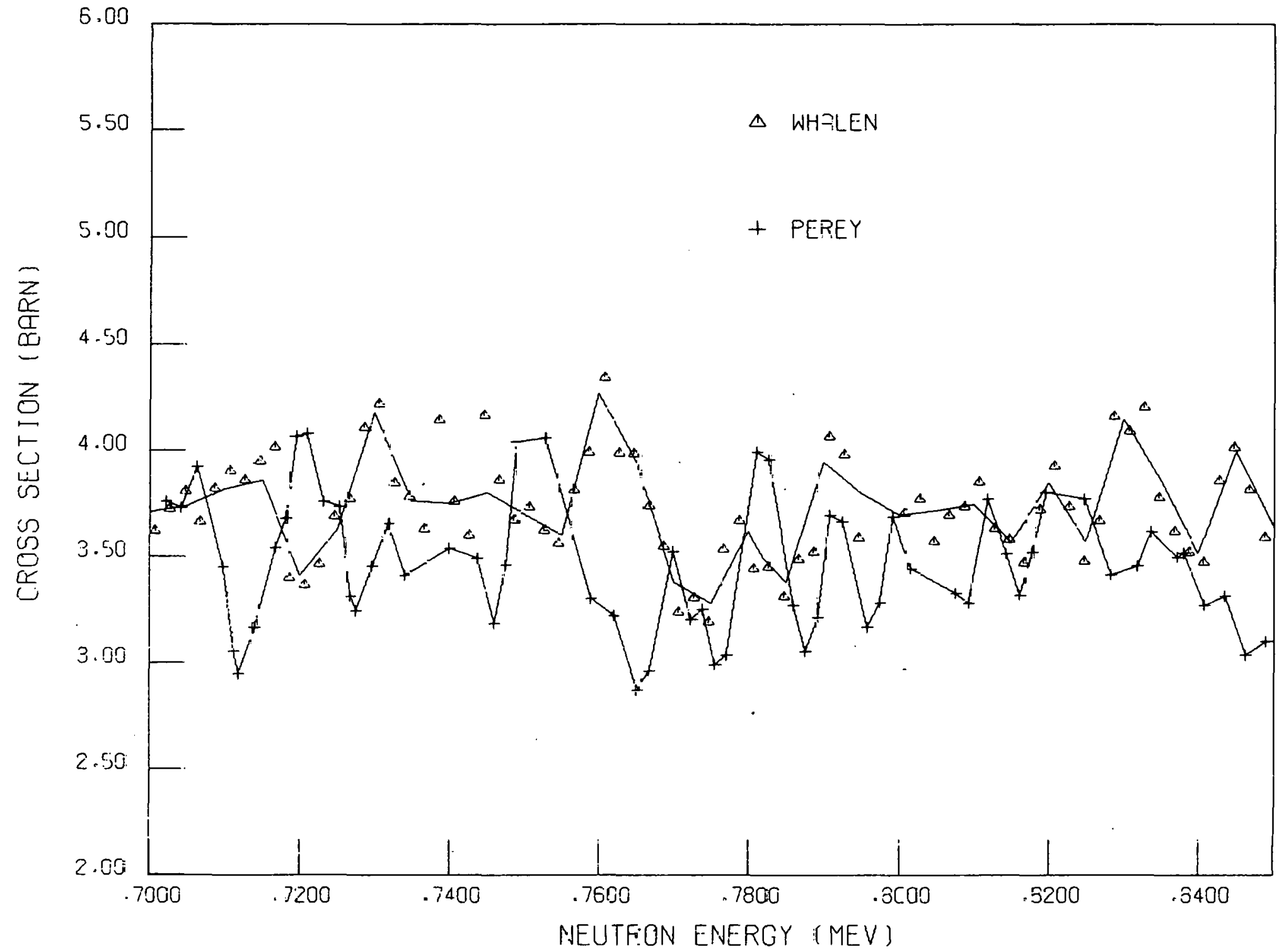

$\ddot{\sigma}$ 


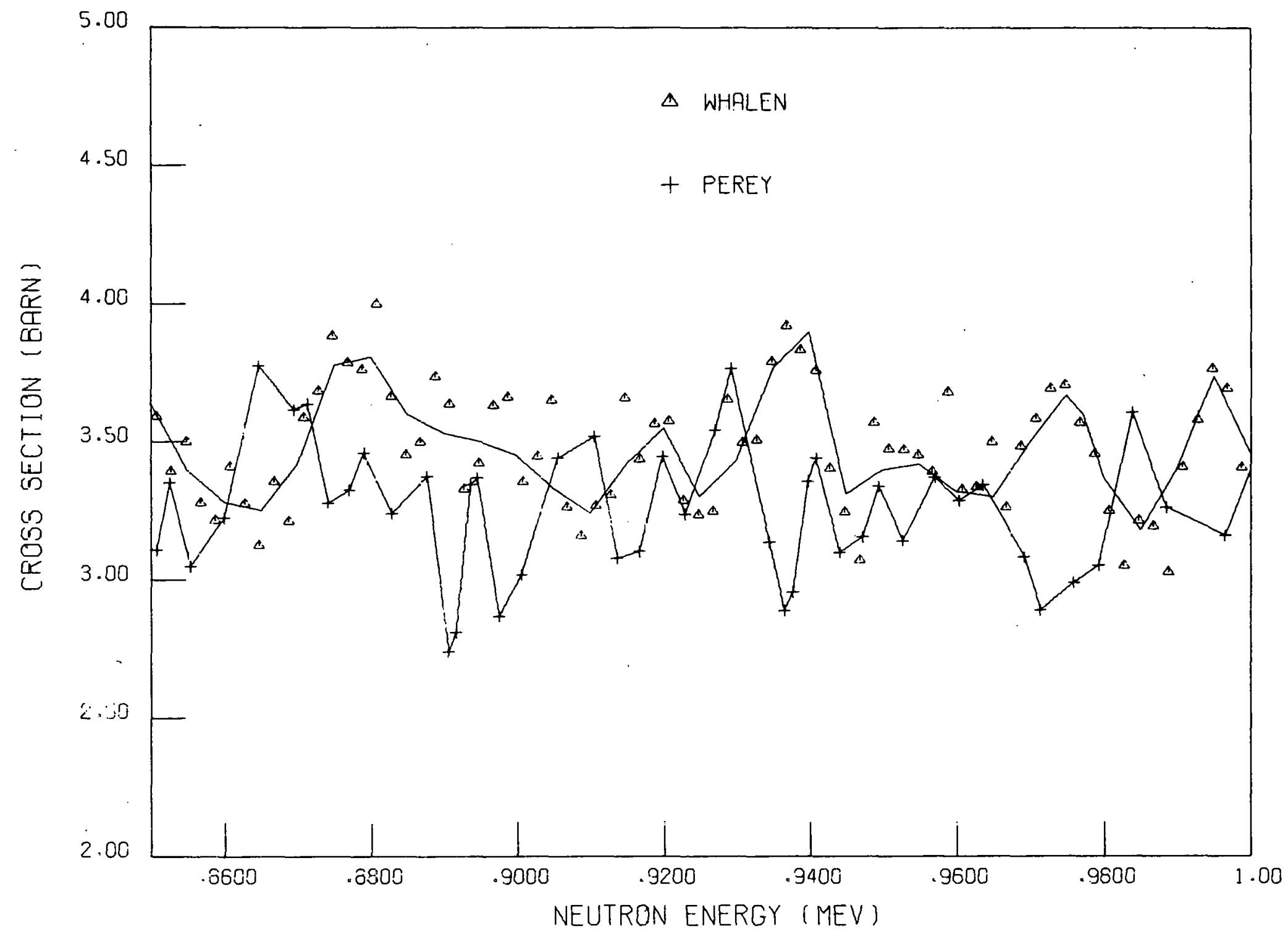




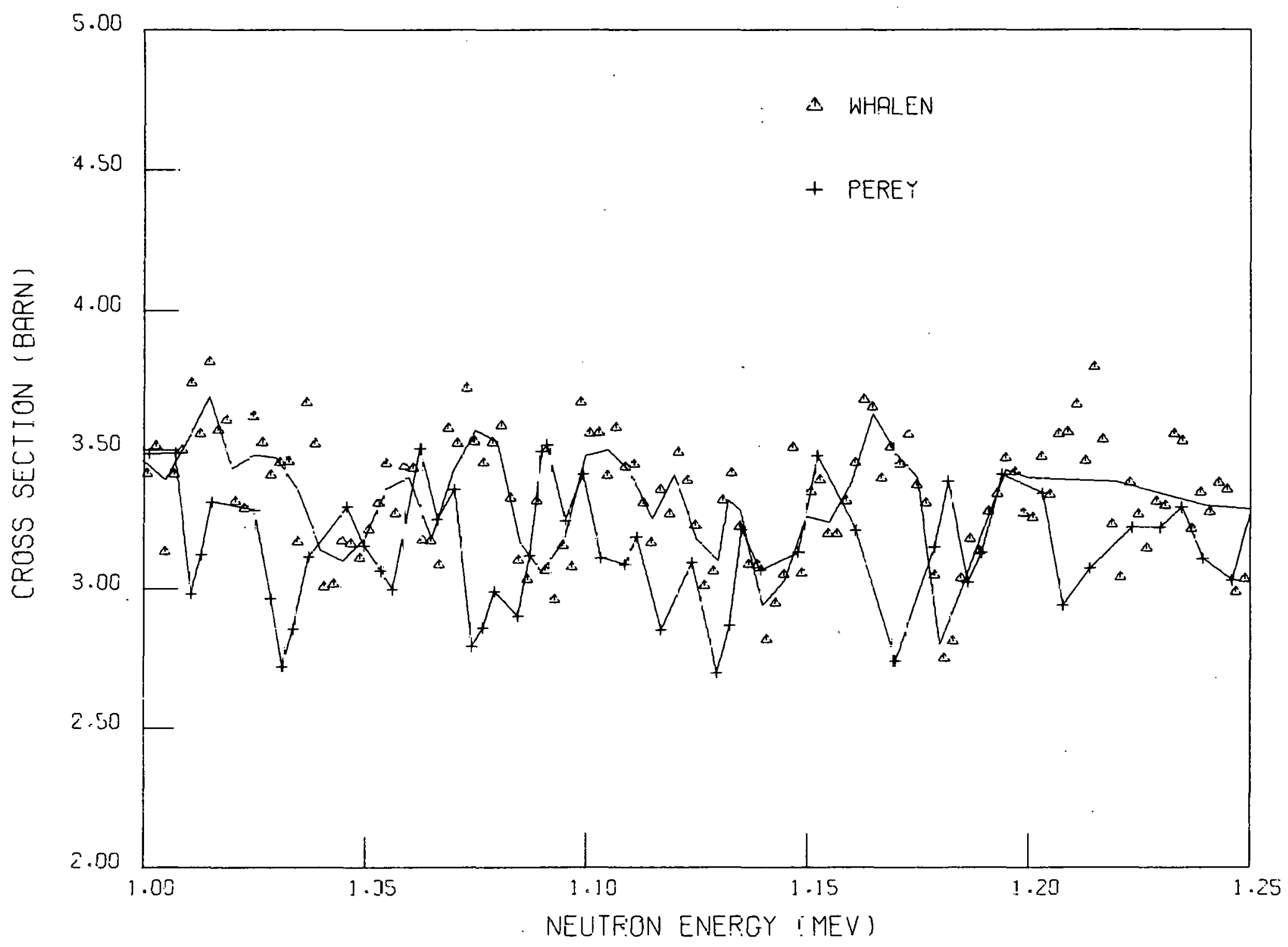




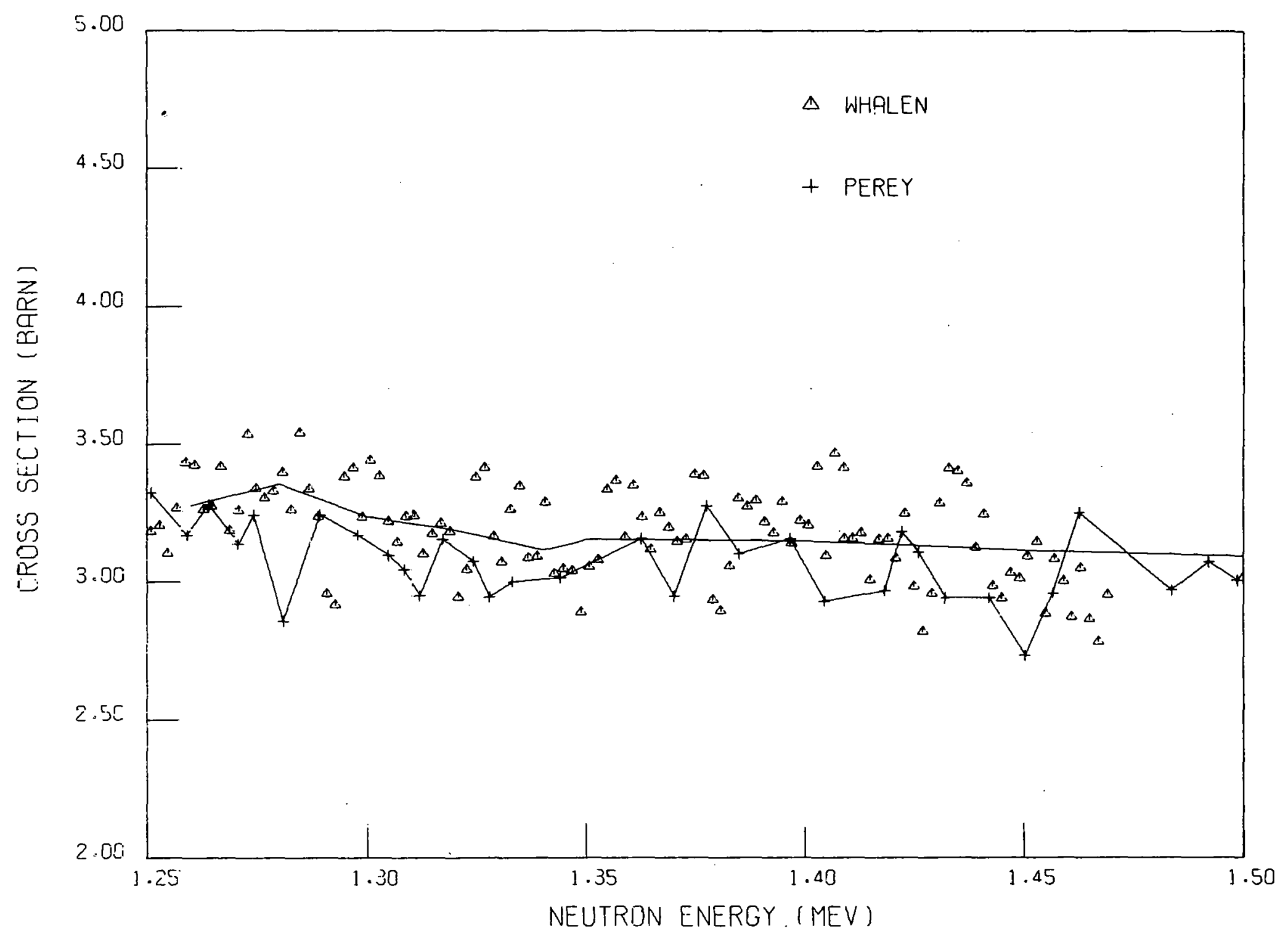

Fig. 24. $\mathrm{Cu}$ total cross sections in ENDF/B-IV and -V (Perey's data). 


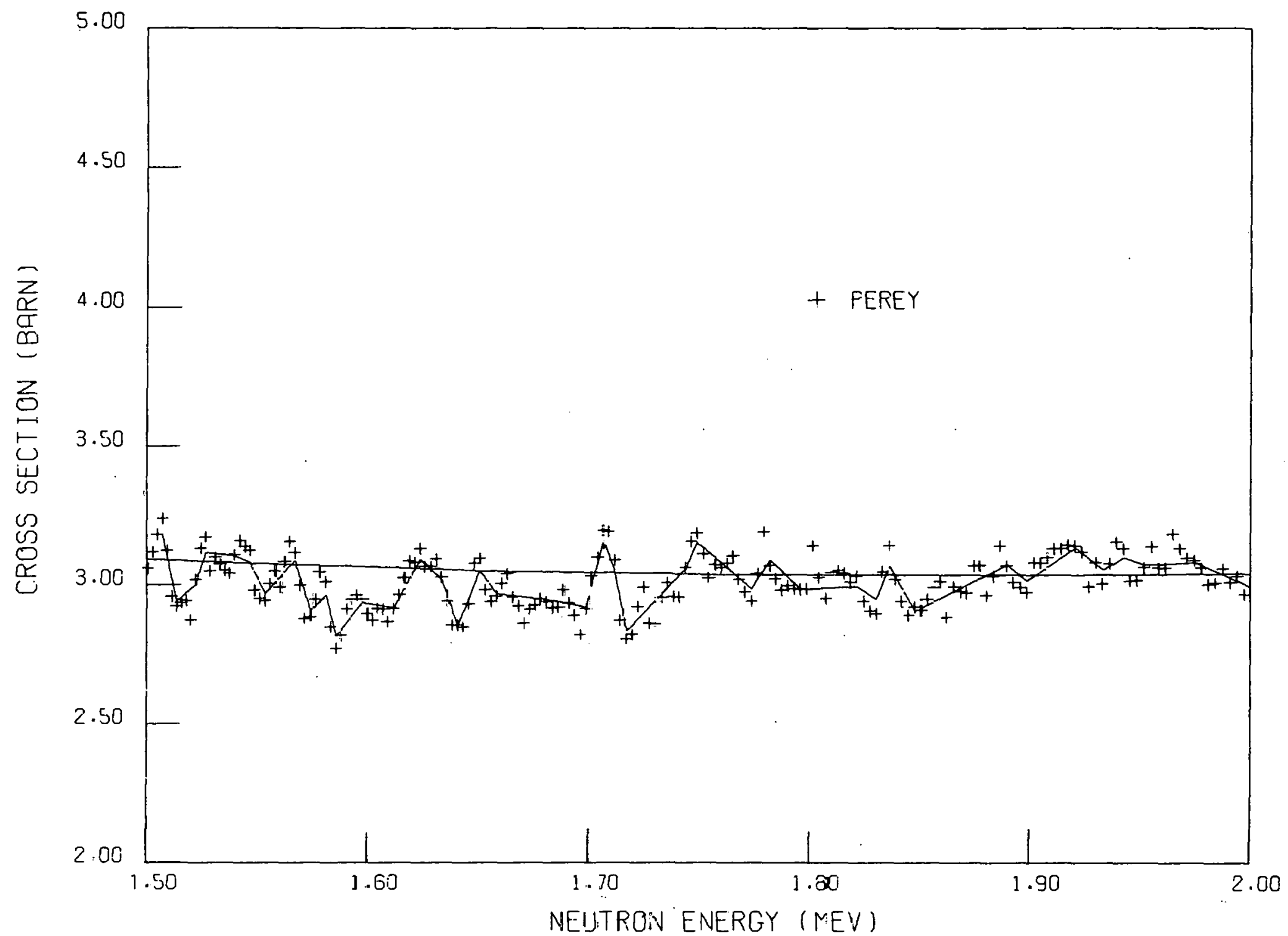

Fig. 25. Cu total cross sections in ENDF/B-IV and -V (Perey's data). 


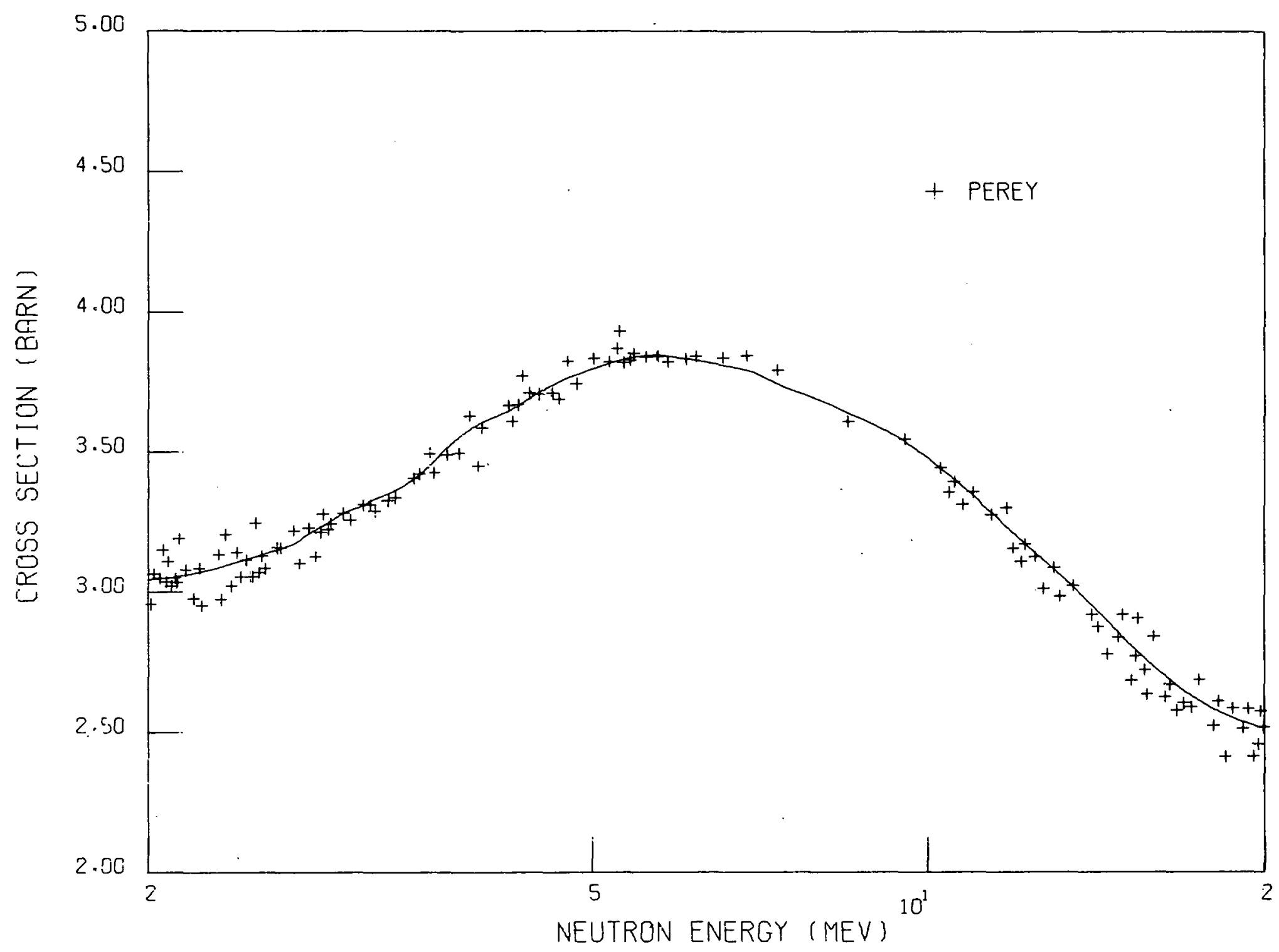
the ENDF/B-IV evaluat:on. 


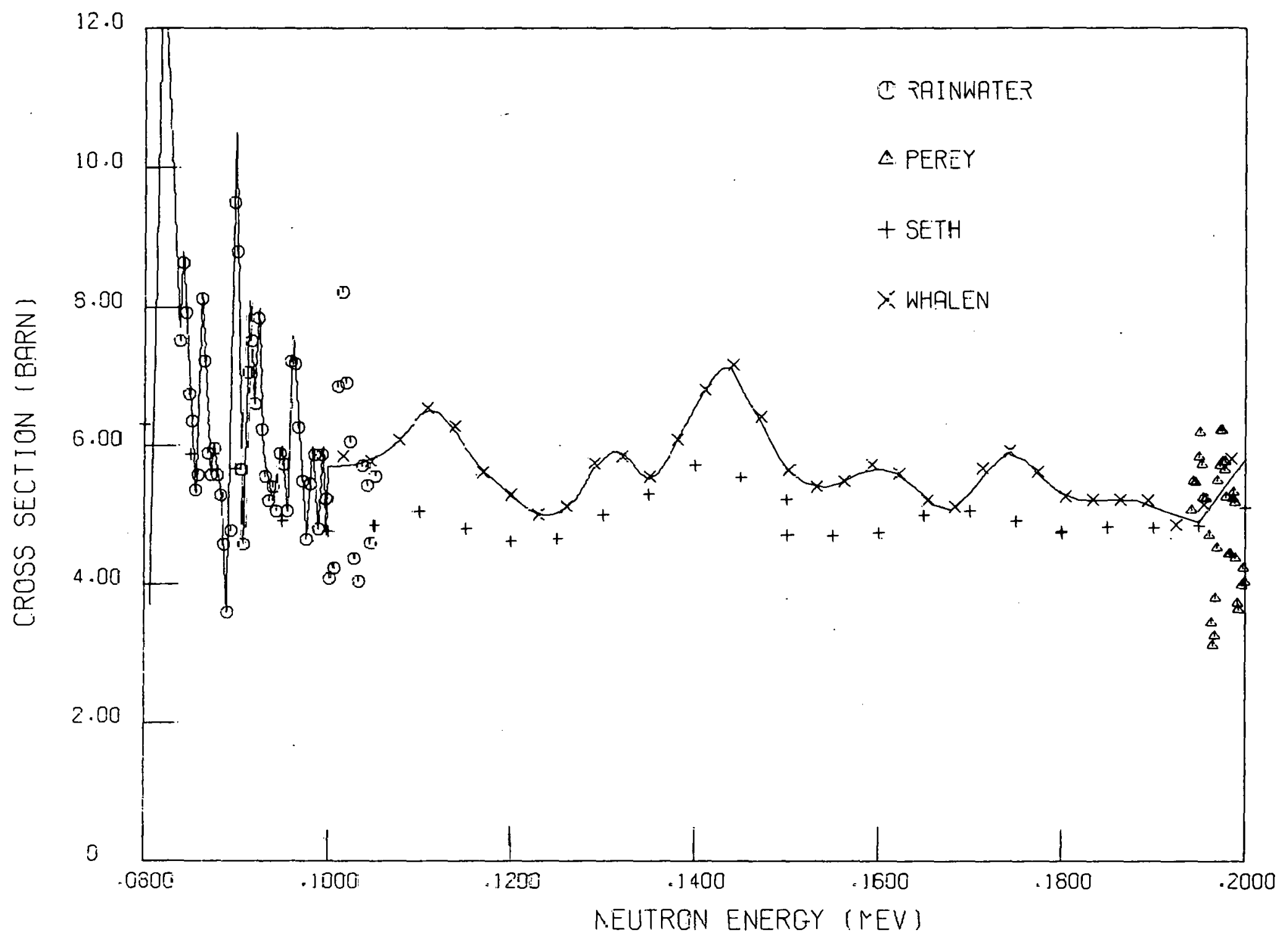

Fig. 27. A comparison of ENDF/B-IV evaluation of the total cross sections for $\mathrm{Cu}$ from $80 \mathrm{keV}$ to $200 \mathrm{keV}$ with the available data. A lack of adequate data between $100 \mathrm{keV}$ and $2010 \mathrm{keV}$ seems to be indicated. 


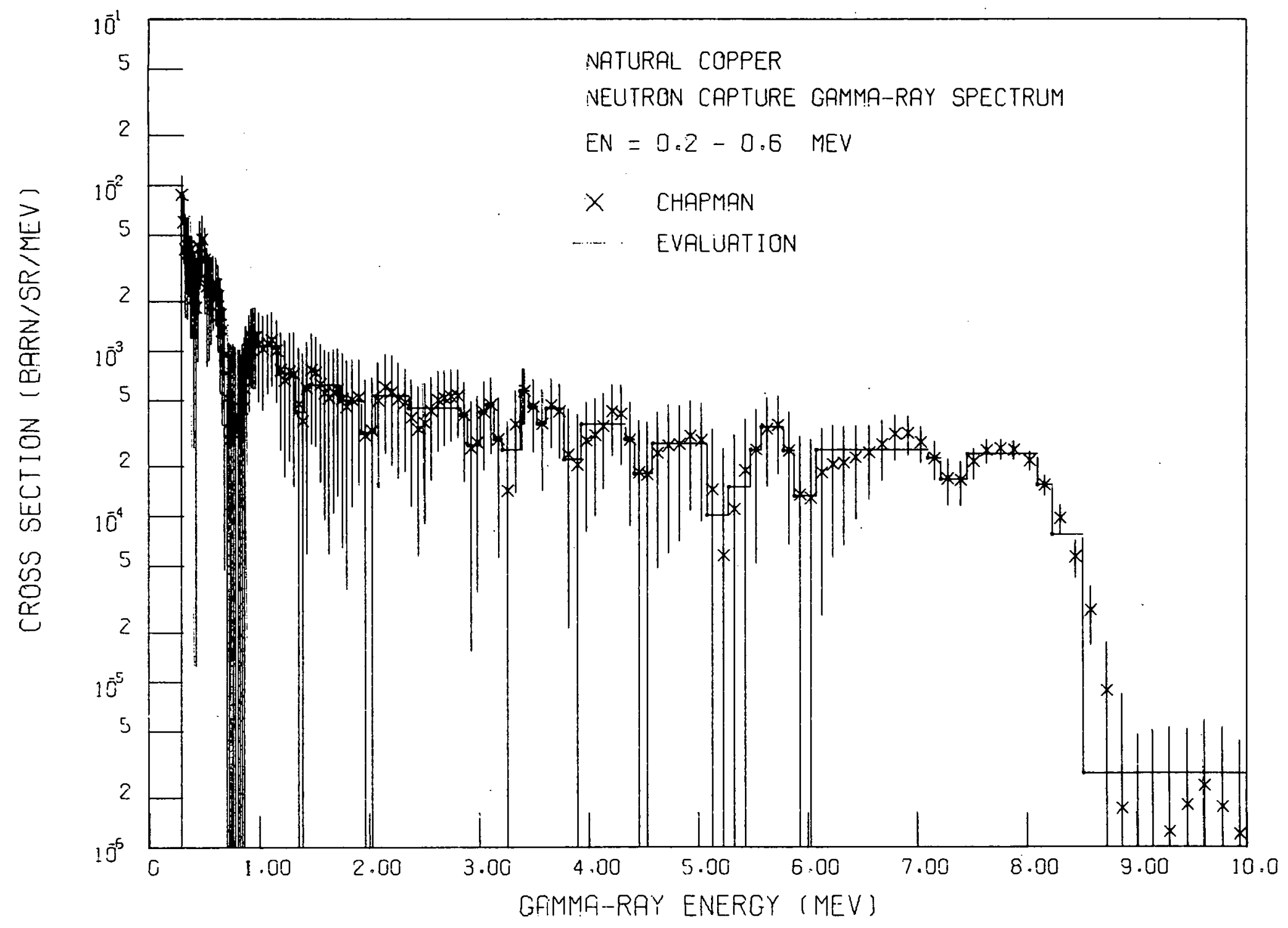

ث

Fig. 28. Capture gamma-ray spectrum for $\mathrm{Cu}$ for $\mathrm{E}_{n}=0.2-0.6 \mathrm{MeV}$. 


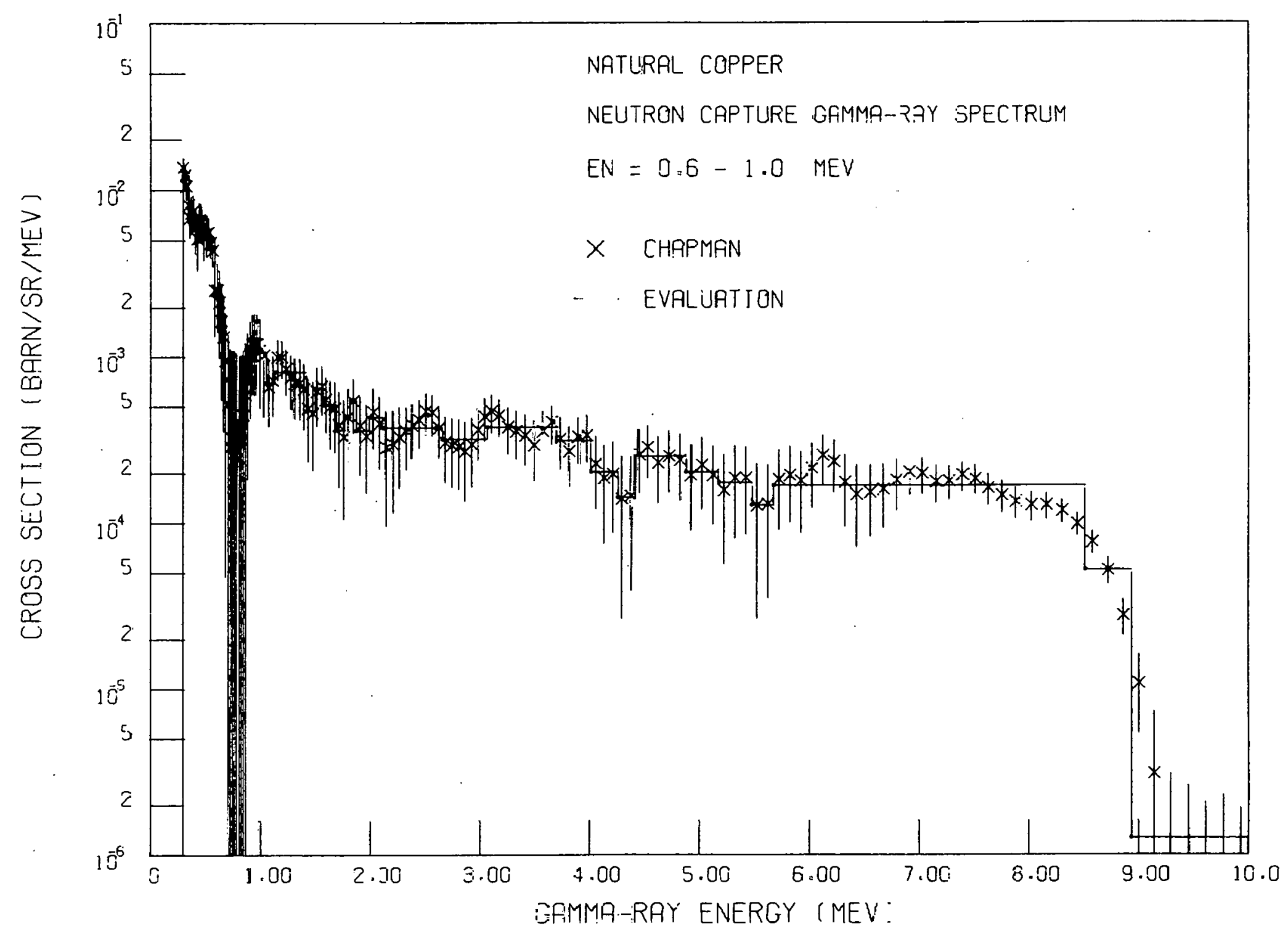
rays due to inelastic scattering were subtracted f:om the data. 


\section{UPDATES FOR LEAD (ENDF/B-V MAT 1382)}

The ENDF/B-III evaluation and part of ENDF/B-IV have been described in detail. ${ }^{10}$ The capture cross sections from $1 \mathrm{keV}$ to $1 \mathrm{MeV}$ were re-evaluated immediately after the ENDF/B-III evaluation was released. Structures in the total and elastic scattering cross sections were adjusted to be consistent with the new capture cross sections. This part of ENDF/B-IV was included in ref. 10. Another modification for ENDF/B-IV was the re-calculation of the neutron emission spectra to include precompound effects similar to the calculation for iron. A comparison of the calculated neutron emission spectrum for $14-\mathrm{MeV}$ incident energy with available data has appeared in a critical review ${ }^{43}$ of neutron emission spectra in ENDF/B-V for sodium, magnesium, aluminum, silicon, calcium, titanium, vanadium, chromium, iron, nickel, copper, niobium, tungsten, and lead. The ENDF/B-V emission spectra for iron and lead were found to be reasonably good. All others were either fair or poor.

Minor updates for ENDF/B-V are described below.

\subsection{GAMMA-RAY PRODUCTION CROSS SECTIONS}

The gamma-ray production cross sections for incident energies from 0.6 to $20 \mathrm{MeV}$ measured by Chapman and Morgan ${ }^{44}$ were adopted. Detailed comparisons of the data with the ENDF/B-IV values and with other available data are given in ref. 44. Since simultaneous analysis of neutron emission spectra and gamma-ray production spectra for each reaction was not performed, there may be inconsistencies in the evaluation, and, in particular, energy conservation may be violated.

\section{$6.2\left(n, n^{\prime}\right),(n, 2 n)$, AND $(n, 3 n)$ CROSS SECTIONS}

The $(n, 2 n)$ cross sections from 7 to $15 \mathrm{MeV}$ were revised according to the recent data of Frehaut and Mosinski. ${ }^{45}$ There were no data available previously in this energy range. The extrapolation to 20 $\mathrm{MeV}$ was based on the ${ }^{204} \mathrm{~Pb}$ data taken from BNL-325. ${ }^{16}$ The $\left(n, n^{\prime}\right)$ and the $(n, 3 n)$ cross sections were revised accordingly to conserve the total reaction cross sections. Figure 30 compares these new values with FNDF/B-IV and the available data. 


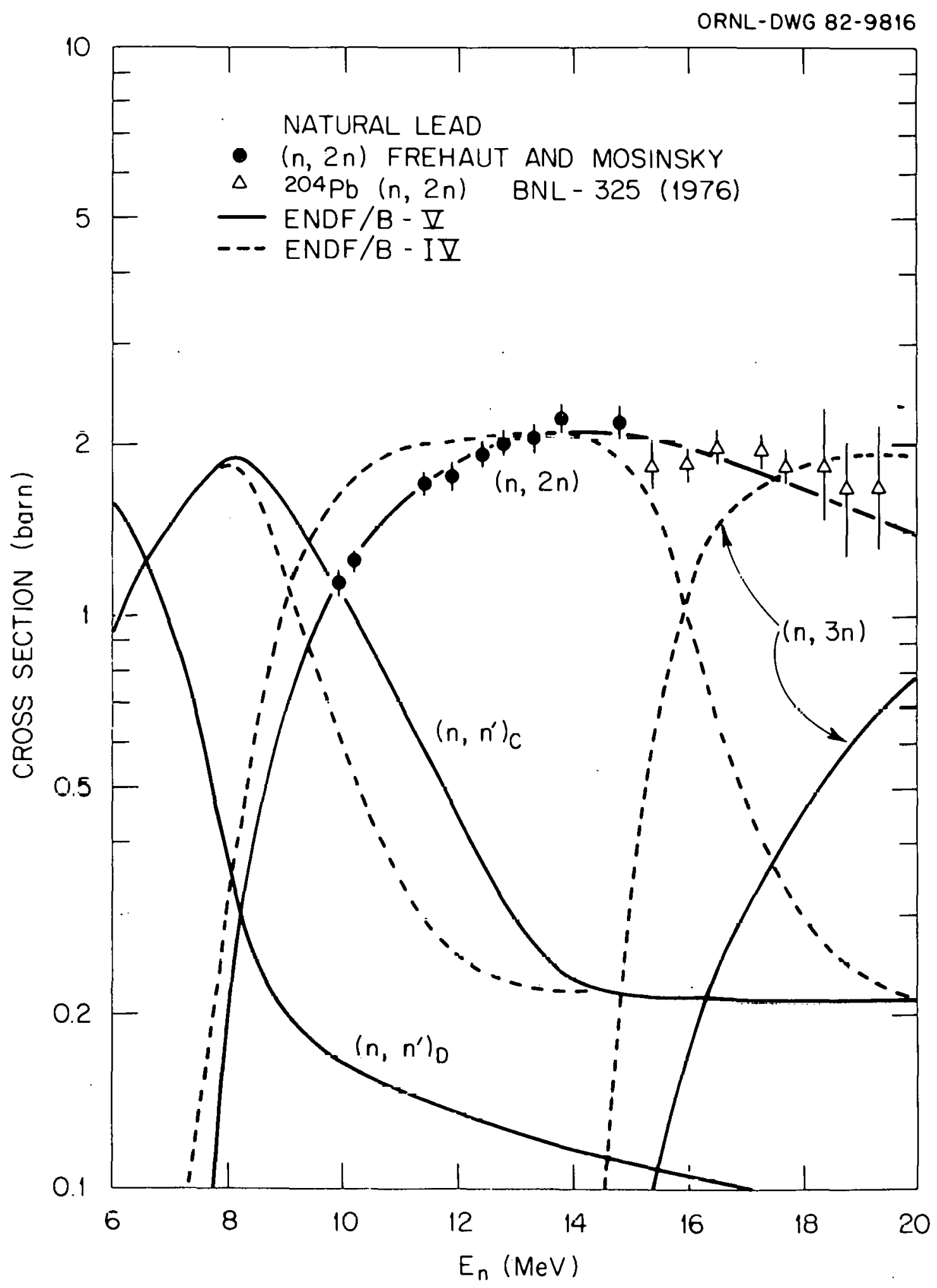
dala.

Fig. 30. The $\mathrm{Pb}\left(n, \mathrm{n}^{\prime}\right),(n, 2 n)$, and $(n, 3 n)$ cross sections in ENDF/B-IV and $-V$ and experimental 


\subsection{CAPTURE CROSS SECTIONS}

From 3 to $20 \mathrm{MeV}$, several sets of capture cross sections are available for ${ }^{208} \mathrm{~Pb}$ in BNL-325. ${ }^{16}$ The only measured cross section for natural lead above $3 \mathrm{MeV}$ is at $14.1 \mathrm{MeV}$ by Cvelbar. ${ }^{46}$ This value is in good agreement with the ${ }^{208} \mathrm{~Pb}$ data. Therefore, the eye-guide curve drawn in BNL-325 through the available data of ${ }^{208} \mathrm{~Pb}$ from 3 to $20 \mathrm{MeV}$ for ENDF/B-V was taken.

\subsection{COVARIANCE FILE}

Covariance data were given for total, elastic scattering, non-elastic, inelastic, $(n, 2 n),(n, 3 n)$, and capture cross sections. Derived sections (NC subsections) reflect how the cross-section files were generated.

In general, covariances were determined from $\pm 2 \sigma$ error bands where data exist. The error bands were extended and enlarged to cover energy regions lacking experimental data. Long-range covariances reflect systematic errors common to all data sets. Medium-range covariances reflect differences in energy coverage by different data sets and differences in experimental techniques within the same data sets. Short-range covariances reflect meaningful structures in the cross sections and/or threshold effects. Statistical errors are nonexistent in the evaluated cross sections.

As in the case of iron, ${ }^{5}$ absolute uncertainties were used, in addition to fractional uncertainties, to help keep the files short. The absolute components are the most useful for total cross-section minima and near thresholds.

Most cross sections for lead were evaluated with guidance from model calculations. However, for energy regions in which model calculations were used directly, uncertainty estimates were based on a general understanding of the adequacy or inadequacy of various models rather than on model parameter variations. 


\section{CONCLUSIONS AND RECOMMENDATIONS}

Noted below are the areas where evaluations can be improved, where data are needed, where new data have become available, and where improved nuclear model codes can be put to good use.

Carbon. The existing information ${ }^{11}$ for neutron emission spectra from ${ }^{12} \mathrm{C}\left(\mathrm{n}, \mathrm{n}^{\prime} 3 \alpha\right)$ reaction remains poor, and no credible nuclear model is available to aid the evaluation. Also, neutron-energy distribution measurements for at least five angles are needed.

High-resolution total and differential elastic scattering cross sections for ${ }^{13} \mathrm{C}$ by Lane et al. ${ }^{48}$ could be used to improve the existing evaluation up to $4.81 \mathrm{MeV}$, particularly the standard scattering cross sections below $2 \mathrm{MeV}$.

Calcium: The recent measurement ${ }^{49}$ for the $(n, p)$ cross sections suggests that our evaluation for these cross sections for $\mathrm{E}_{n}$ between 3 and $6 \mathrm{MeV}$ should be lowered by about $30 \%$. Since the (n,p) cross sections in this energy range are the largest of all reaction cross sections, a reduction as large as $30 \%$ should not be made without carefully studying its impact on other cross sections.

Iron. A recent study ${ }^{50}$ of the radiative width of the $27.7-\mathrm{keV} \mathrm{s}$-wave resonance in ${ }^{56} \mathrm{Fe}$ yields 1.01 $\mathrm{eV}$ as opposed to our evaluated value of $1.4 \mathrm{eV}$. The indicated reduction would not only reduce neutron capture in nuclear reactors and shields but also reduce the total cross section at the $24.3-\mathrm{keV}$ minimum by about $20 \% .^{51}$

For $14-\mathrm{MeV}$ incident neutron, the measured angular distributions ${ }^{52,53}$ for outgoing neutrons between 4 and $10 \mathrm{MeV}$ show a factor of two anisotropy (ratio of forward emission to 90-degree emission in the center-of-mass frame). These angular distributions have been reproduced with our improved version of the TNG code. ${ }^{54}$ This model analysis could be used to generate complete angular spectra in evaluated form for incident neutron energies between 5 and $20 \mathrm{MeV}$.

High-quality data $\mathrm{a}^{34,36}$ for the proton and alpha-particle production cross sections at $14.8 \mathrm{MeV}$ exist for iron but have not been used in the evaluation. The corresponding evaluated cross section for alphaparticle production is in good agreement with this new information, but the evaluated value for protons is $22 \%$ lower. A recent model analysis ${ }^{9}$ reproduces these new data well but has not been generalized to include gamma-ray production. 
Copper. As indicated, the total cross sections between 100 and $200 \mathrm{keV}$ need to be refined. A recent, but not yet published, measurement by Harvey ${ }^{55}$ should be examined.

Two measured spectra of gamma rays produced by thermal neutron capture are in a factor-of-two disagreement. One is by Orphan et al. ${ }^{56}$ and the other by Maerker and Muckenthaler. ${ }^{57}$ The former $^{56}$ was adopted in the evaluation and could be the wrong choice. These data should be examined more carefully, perhaps with the aid of nuclear model analysis.

The 14-MeV neutron emission spectrum in copper lacks a high-energy tail (the precompound component) as indicated by direct comparison ${ }^{43}$ with available data and by analysis ${ }^{58}$ of the leakage spectrum from a sphere pulsed with $14-\mathrm{MeV}$ neutrons.

Energy imbalances in the copper evaluation could not be checked ${ }^{25}$ because of the "elemental Qvalue" problem but are known to exist. ${ }^{59}$ The problem could be solved by performing isotopic evaluations for ${ }^{63} \mathrm{Cu}$ and ${ }^{65} \mathrm{Cu}$.

Improved evaluations for the ${ }^{63} \mathrm{Cu}(\mathrm{n}, \alpha)$ and the ${ }^{63,65} \mathrm{Cu}(\mathrm{n}, 2 \mathrm{n})$ cross sections now exist ${ }^{60}$ and should be adopted in the general-purpose file. The evaluations were based on the generalized least-squares techniques and made use of ratio data.

Lead. Energy imbalances in the lead evaluation are known to exist. ${ }^{25}$ This is expected since several partial updates were made to the originally consistent evaluation. ${ }^{10}$ Consistent model analysis for lead is time-consuming because calculations must be made for three isotopes. An update similar to that done for the iron evaluation may be advisable.

In conclusion, it should be noted that good evaluations eventually become obsolete, at least partially, as more accurate data become available and as more advanced nuclear model codes and evaluation tools are developed. In addition, improvements in computing facilities and transport codes, as well as new applications, invariably call for more details in the evaluated data.

\section{ACKNOWLEDGEMENT}

The author thanks D. M. Hetrick for his help in developing a computer program that checks energy balance in the ENDF/B-V evaluations. 


\section{REFERENCES}

1. C. Y. Fu and F. G. Perey, Atom. Data Nucl. Data Tables, 22, 249 (1978).

2. C. Y. Fu and F. G. Perey, "Neutron Scattering Cross Sections of Carbon below $2 \mathrm{MeV}$ for ENDF/B-V," in ENDF/B-V Cross Section Measurements Standards, Ed(s). A. D. Carlson and M. R. Bhat, Brookhaven National Laboratory Report (in press).

3. C. Y. Fu, Atom. Data Nucl. Data Tables 17, 127 (1976).

4. D. M. Hetrick and C. Y. Fu, A Culculation of Neutron and Gamma-Ray Production Cross Sections for Calcium from 8 to $20 \mathrm{MeV}$, ORNL/TM-7752, ENDF-308, Oak Ridge National Laboratory, Oak Ridge, Tenn., 1981.

5. C. Y. Fu and F. G. Perey, Evaluation of Neutron and Gamma-Ray Production Cross Sections for Natural Iron (ENDF/B-V MAT 1326), ORNL/TM-7523, ENDF-302, Oak Ridge National Laboratory, Oak Ridge, Tenn., November 1980.

6. C. M. Perey and F. G. Perey, Evaluation of Resonance Parameters for Neutron Interaction with Iron Isotopes for Energies up to $100 \mathrm{keV}$, ORNL/TM-6405, ENDF-298, Oak Ridge National Laboratory, Oak Ridge, Tenn., Sepember 1980.

7. C. Y. Fu, "A Two-Step Hauser-Feshbach Model Code with Precompound Effects and Gamma-Ray Cascades," p. 328 in Nuclear C'ross Sections and Technology, Proc. Conf., Vol. I, National Bureau of Standards Special Publication SP-425, 1975.

8. J. E. White, C. Y. Fu, and K. J. Yost, Nucl. Sci. Eng., 51, 496 (1973).

9. C. Y. Fu, A Consistent Nuclear Model for Compound and Precompound Reactions with Conservation of Angular Momentum, ORNL/TM-7042, Oak Ridge National I.ahoratnry, Oak Ridge, Tenn., May 1980.

10. C. Y. Fu and F. G. Perey, Atom. Data Nucl. Data Tables, 16, 409 (1975). 
11. J. Lachkar et al., An Evaluation of the Neutron-Induced Scattering Reaction and Photon-Production Cross Sections of Carbon, NEANDC(E) 168 "L", INDC (FR-7/L, 1975.

12. G. M. Frye, Jr., L. Rosen, and L. Stewart, Phys. Rev. 99, 1375 (1955).

13. B. Antolkovic and Z. Dolenec, Nucl. Phys., A237, 235 (1975).

14. B. Antolkovic and J. Hudomalj, Nucl. Phys., A237, 253 (1975).

15. U. N. Singh, Phys. Rev., C10, 2143 (1974).

16. D. I. Garber and R. R. Kinsey, Neutron Cross Sections, BNL-325, Third Edition, Vol. II, Brookhaven National Laboratory, Upton, N.Y., 1976.

17. B. J. Allen et al., "Neutron Capture Mechanism in Light and Closed Shell Nuclides," p. 360 in Proc. Conf. Nucl. Cross Sections and Tech., NBS-SP-425, 1975.

18. A. R. De L. Musgrove et al., "Odd-Even Effects in Radiative Neutron Capture by Ca-42, Ca-43, Ca-44," Nucl. Phys. A279, 317 (1977).

19. F. Cvelbar, NIJS-R-505, Inst. Josef Stefan, Ljubljana, Yugoslavia, 1967.

20. M. Kawai, N. Yamano, and K. Koyama, "Request to Evaluating Neutron Cross Section of Structural Material for Shielding Application," p. 586 in Proc. Conf. Nucl. Cross Sections for Tech., NBS-SP-594, 1979.

21. A. B. Smith, Argonne National Laboratory, personal communication to C. Y. Fu, Oak Ridge National Laboratory, Oak Ridge, Tenn., 1980.

22. C. M. Lederer and V. S. Shirley, Table of Isotopes, 7th Edition, 1978.

23. E. D. Arthur and P. G. Young, Evaluated Neutron-Induced Cross Sections for ${ }^{54,56}{ }^{\mathrm{Fe}}$ to $40 \mathrm{MeV}$, LA^8626-MS, ENDF-304, Los Alamos Scientific Laboratory, 1980.

24. A. Gilbert and A. G. W. Cameron, Can. J. Phys. 43, 1446 (1965).

25. R. E. MacFarlane, "Energy Balance of ENDF/B-V," Trans. Am. Nucl. Soc. 33, 681 (1979). 
26. C. Y. Fu and F. G. Perey, "Summary Documentation for Iron (MAT 1192)," in ENDF/B Summary Documentation compiled by D. Garber, ENDF-201, 2nd edition, 1975.

27. V. J. Orphan, C. G. Hoot, and Joseph John, Gulf Radiation Technology Report RT-A10753, 1971; revision by V. C. Rogers, Intelcom Radiation Technology, personal communication, 1973.

28. J. K. Dickens, G. L. Morgan, and F. G. Perey, Nucl. Sci. Eng. 50, 311 (1973).

29. G. T. Chapman, G. L. Morgan, and F. G. Perey, A Re-Measurement of the Neutron-Induced Gamma-Ray Production Cross Sections for Iron in the Energy Range $850 \mathrm{keV}<E_{n}<20.0 \mathrm{MeV}$, ORNL/TM-5416, Oak Ridge National Laboratory, Oak Ridge, Tenn., July 1976.

30. D. M. Drake, E. D. Arthur, and M. G. Silbert, Nucl. Sci. Eng. 65, 49 (1978).

31. M. K. Drake and M. P. Fricke, "Evaluation of Neutron and Photon-Production Cross Sections for Natural Copper," DNA-3356F, Defense Nuclear Agency, 1974.

32. D. L. Allan, Nucl. Phys. 24, 274 (1961).

33. R. S. Storey, Proc. Phys. Soc. 75, 526 (1960).

34. S. M. Grimes, Phys. Rev. C19, 2127 (1979). R. C. Haight and S. M. Grimes, UCRL-80235, Lawrence Livermore Laboratory, 1977, and personal communication, 1977.

35. F. M. Mann and R. E. Schenter, "He Production - An Example of Hauser-Feshbach Calclations," in Symp. on Neutron Cross Sections from 10 to $40 \mathrm{MeV}$, BNL-NCS-50681, Brookhaven National Laboratory, 1977.

36. H. Farrar IV and D. W. Knoff, "Helium Gerieration In Twelve l'ure Llements at $14.8 \mathrm{MeV}$," Trans. Am. Nucl. Soc. 28, 197 (1978), and personal communication, 1977.

37. H. Alter, in ENDF/B-IV Dosimetry Files, ed. B. A. Magurno, BNL-NCS-50446, ENDF-216, Brookhaven National Laboratory, 1975.

38. F. G. Perey, Oak Ridge National Laboratory, personal communication with C. Y. Fu, Oak Ridge National Laboratory, 1976. 
39. J. F. Whalen, CSISRS data tape (1970).

40. K. K. Seth, Phys. Lett., 16, 306 (1965).

41. J. Rainwater, Bull. Am. Phys. Soc., 8, 334 (1962).

42. G. T. Chapman, The $C u(n, x \gamma)$ Reaction Cross Section for Incident Neutron Energies Between 0.2 and $20.0 \mathrm{MeV}$, ORNL/TM-5215, Oak Ridge National Laboratory, Oak Ridge, Tenn., February 1976.

43. D. M. Hetrick, D. C. Larson, and C. Y. Fu, "Neutron Emission Spectra Induced by 14-MeV Neutrons from the Evaluated Nuclear Data File (ENDF/B-V) - A Critical Review," p. 765 in Proc. Conf. on Nucl. Cross Sections for Tech., NBS-SP-594, 1979.

44. G. T. Chapman and G. L. Morgan, The $P b(n, x \gamma) \mathrm{I}$ Reaction for Incident Neutron Energies Between 0.6 and $20 \mathrm{MeV}$, ORNL/TM-4822, Oak Ridge National Laboratory, Oak Ridge, Tenn., February 1975.

45. J. Frehaut and G. Mosinski, "Measurement of $(n, 2 n)$ and $(n, 3 n)$ Cross Sections at Incident Energies Between 8 and $5 \mathrm{MeV}$," 5th Int. Symp. on Interaction of Fast Neutrons with Nuclei, Gaussig, DDK, 1975.

46. F. Cvelbar, Nucl. Instr. Meth. 44, 292 (1966).

47. G. F. Auchampaugh, S. Plattard, and N. W. Hill, Nucl. Sci. Eng., 69, 30 (1979).

48. R. O. Lane et al., Phys. Rev. C23, 1883 (1981).

49. C. Murray Bartle, University of Cape Town, South Africa, personal communication, 1976.

50. K. Wischak and F. Kappeler, Nucl, Sçi. Eng. 77, 58 (1981).

51. H. I. Liou, Nucl. Sci. Eng., 70, 150 (1979). 
52. D. Hermsdorf, A. Meister, S. Sassonoff, D. Selliger, K. Seidel, and F. Shalin, Differentielle Neutronenemissionsquerschnitte $\sigma_{n M}\left(E_{0} ; E ; 0\right)$ bei $14.6 \mathrm{MeV}$ Einschussenergie fue die Elemente Be, $C$, Na, Mg, Al, Si, P, S, Ca, Ti, V, Cr, Mn, Fe, Co, Ni, Cu, Zn, Ga, Se, Br, Zr, Nb, Cd, In, Sn, Sb, I, Ta, W, $A u, H g, P b$, und Bi, ZKF-277(U), Zentralinstitut fur Kernforschung, 1975.

53. J. L. Kammerdiener, Neutron Spectra Emitted by ${ }^{239} \mathrm{Pu},{ }^{238} \mathrm{U},{ }^{238} \mathrm{U}, \mathrm{Pb}, \mathrm{Nb}, \mathrm{Ni}, \mathrm{Al}$, and C Irradiated by 14-MeV Neutrons, UCRL-51232, University of California, 1972.

54. C. Y. Fu, "Development and Applications of Multi-Step Hauser-Feshbach Pre-equilibrium Model Theory," in Nuclear Theory for Applications - 1980, Proc. Interregional Advanced Training Course on Applications of Nuclear Theory to Nuclear Data Calcuations for Reactor Design, held at Trieste, Jan. 28-Feb. 22, 1980.

55. J. A. Harvey, Oak Ridge National Laboratory, personal communication with C. Y. Fu, Oak Ridge National Laboratory, 1981.

56. V. J. Orphan, C. G. Hoot, and Joseph John, GA-10248, General Atomics, 1970.

57. R. E. Maerker and F. J. Muckenthaler, ORNL-4382. Oak Ridge Natinnal Laboratory, Oak Ridge, Tenn., 1969.

58. R. J. Howerton, Data Testing Results for the ENDF/B-V Evaluated Neutron Data File, UCID18731, Lawrence Livermore Laboratory, 1980.

59. C. Y. Fu, "Evaluation of Photon Production Data from Neutron Induced Reactions," p. 753 in Proc. Conf. on Nucl. Data Evaluation Methods and Procedures, held at Brookhuven National Laboratory, Sept. 22-25. 1980.

60. C. Y. Fu and D. M. Hetrick, "Experience in Using the Covariances of Some ENDF/B-V Dosimetry Cruss Sectiuns: Proposed Improvements and Additions of Cross-Reaction Covariances," Fourth ASTM-EURATM Symposium on Reactor Dosimetry, March 22-26, 1982, National Bureau of Standards, Gaithersburg, Maryland.

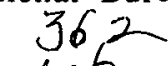

240

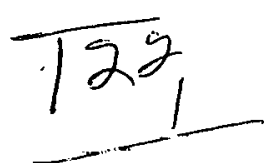




$\begin{array}{ll} & \text { ORNL/TM-8283 } \\ \text { ENDF-325 } \\ \text { Dist. Category UC-79d }\end{array}$

$\begin{aligned} \text { 1-2. } & \text { L. S. Abbott } \\ 3 . & \text { Z. W. Bell } \\ 4 . & \text { G. de Saussure } \\ 5 . & \text { J. K. Dickens } \\ 6-8 . & \text { EPIC } \\ 9 . & \text { G. F. Flanagan } \\ \text { 10-14. } & \text { C. Y. Fu } \\ 15 . & \text { J. A. Harvey } \\ 16 . & \text { D. M. Hetrick } \\ 17 . & \text { D. C. Larson } \\ \text { 18-22. } & \text { F. C. Maienschein } \\ 23 . & \text { D. K. Olsen } \\ 24-28 . & \text { R. W. Peelle } \\ 29 . & \text { F. G. Perey } \\ 30 . & \text { R. W. Roussin }\end{aligned}$

31. C. R. Weisbin

32. L. W. Weston

33. A. Zucker

34. P. W. Dickson, Jr. (consultant)

35. H. J. C. Kouts (consultant)

36. W. B. Loewenste in (consuTtant)

37. Richard Wilson (consultant)

38-39. Laboratory Records

40. Laboratory Records-RC

41. ORNL Patent Office

42. Central Research Library

43. ORNL Y-12 Technical Library

Document Reference Section

\section{EXTERNAL DISTRIBUTION}

44. Office of Assistant Manager for Energy Research and Development, Department of Energy, Oak Ridge Operations, Oak Ridge, TN 37830

45. M. R. Bhat, Building 197D, National Nuclear Data Center, Brookhaven National Laboratory, Upton, Long Is land, NY 11973

46. Phillip B. Hemmig, Reactor Physics Branch, Division of Reactor Research and Technology, DOE, Washington, DC 20615

47. R. J. Howerton, L-71, Lawrence Livermore Laboratory, P. 0. Box 808 , Livermore, CA 94550

48. Odelli Ozer, Nuclear Safety and Analysis Department, Electric Power Research Institutc, 3412 Hillview Avenue, F. 0. Box 10412, Palo Alto, CA 94304

49. S. Pearlstein, Building 197D, National Nuclear Data Center, Brookhaven National Laboratory, Upton, Long Island, NY 11973

50. Robert Schenter, Hanford Engineering Development Laboratory, P. 0. Box 1970, Richland, WA 99352

51. Stanley Whetstone, Division of Basic Energy Sciences, Department of Energy, Washington, DC 20545

52. P. G. Young, Los Alamos Scientific Laboratory, Los Alamos, NM 87545

53. S. Berk, Office of Fusion Energy, Department of Energy, Washington, DC 20545

54. E. T. Cheng, General Atomic Company, San Diego, CA

55-81. Technical Information Center, U. S. Department of Energy, Oak Ridge, TN 37830

8́-171. Mary Rizzi, Nationäl Nuclear Data Center, ENDF, Brookhaven National Laboratory, Upton, Long Island, NY 11973

172-239. DNA Transport Distribution, Code AU

240-362. For distribution as shown in TID-4500 Distribution Category UC-79d, Liquid Metal Fast Breeder Reactor Physics - Base Technology. 